\title{
Molecular Targeted Therapy and Immunotherapy for Myelodysplastic Syndrome
}

\author{
Paul Lee, Rita Yim (D), Yammy Yung, Hiu-Tung Chu, Pui-Kwan Yip and Harinder Gill *(D) \\ Division of Haematology, Medical Oncology and Haemopoietic Stem Cell Transplantation, Department of \\ Medicine, LKS Faculty of Medicine, The University of Hong Kong, Hong Kong, China; pl85@hku.hk (P.L.); \\ ritayim@hku.hk (R.Y.); u3558354@hku.hk (Y.Y.); u3557654@hku.hk (H.-T.C.); u3557642@hku.hk (P.-K.Y.) \\ * Correspondence: gillhsh@hku.hk; Tel.: +852-2255-4542; Fax: +852-2816-2863
}

Citation: Lee, P.; Yim, R.; Yung, Y.; Chu, H.-T.; Yip, P.-K.; Gill, H. Molecular Targeted Therapy and Immunotherapy for Myelodysplastic Syndrome. Int. J. Mol. Sci. 2021, 22, 10232. https://doi.org/10.3390/ ijms 221910232

Academic Editor:

Theodoros Karantanos

Received: 31 August 2021

Accepted: 21 September 2021

Published: 23 September 2021

Publisher's Note: MDPI stays neutral with regard to jurisdictional claims in published maps and institutional affiliations.

Copyright: (C) 2021 by the authors. Licensee MDPI, Basel, Switzerland. This article is an open access article distributed under the terms and conditions of the Creative Commons Attribution (CC BY) license (https:/ / creativecommons.org/licenses/by/ $4.0 /)$.

\begin{abstract}
Myelodysplastic syndrome (MDS) is a heterogeneous, clonal hematological disorder characterized by ineffective hematopoiesis, cytopenia, morphologic dysplasia, and predisposition to acute myeloid leukemia (AML). Stem cell genomic instability, microenvironmental aberrations, and somatic mutations contribute to leukemic transformation. The hypomethylating agents (HMAs), azacitidine and decitabine are the standard of care for patients with higher-risk MDS. Although these agents induce responses in up to $40-60 \%$ of patients, primary or secondary drug resistance is relatively common. To improve the treatment outcome, combinational therapies comprising HMA with targeted therapy or immunotherapy are being evaluated and are under continuous development. This review provides a comprehensive update of the molecular pathogenesis and immune-dysregulations involved in MDS, mechanisms of resistance to HMA, and strategies to overcome HMA resistance.
\end{abstract}

Keywords: myelodysplastic syndromes; hypomethylating agents; treatment resistance; targeted therapy; immunotherapy

\section{Introduction}

Myelodysplastic syndrome (MDS) is a hematological disorder characterized by ineffective hematopoiesis, cytopenia, and the propensity of clonal progression to acute myeloid leukemia. The Revised International Prognostic Scoring System (IPSS-R) is the most commonly used prognostic tool for predicting the risk of leukemic transformation and overall survival. Patients with lower-risk MDS (LR-MDS) are managed largely with supportive care and agents targeting improvements in anemia. Patients with higher-risk MDS (HR-MDS) are treated with the hypomethylating agents, azacitidine (AZA) or decitabine (DEC) [1]. Allogeneic hematopoietic stem cell transplant (HSCT) remains the only curative treatment for HR-MDS patients but is only limited to younger patients who are fit for allogeneic HSCT with suitable donors [2].

Clonal evolution studies of MDS stem cells have shown that $\mathrm{CD}_{123^{+}} \mathrm{MDS}$ malignant stem cells are more abundant in HR-MDS than LR-MDS patients and this stem population is enriched for protein synthesis activity despite they are quiescent [3]. The clinical heterogeneity of MDS is attributed to multiple genetic and epigenetic aberrations resulting in the dysplastic and proliferative features of MDS. In addition, MDS is characterized by a heterogenous immunopathology involving both innate and adaptive immunity. In general, cytopenia in LR-MDS is attributed to inflammation and apoptosis of progenitor cells and clonal expansion of dominant cell lineage in HR-MDS is associated with evasion of immune checkpoints [4].

\section{Molecular Pathogenesis of MDS}

Karyotypic abnormalities are seen in approximately $30-50 \%$ of patients with MDS and correlated with prognosis [5-7]. On the other hand, mutations are detectable by 
next generation sequencing (NGS) in more than $80 \%$ of patients with MDS with distinct mutation profiles observed in different MDS subtypes [8-12]. Multiple studies have tried to incorporate mutation profiling by NGS into the IPSS-R or WHO classification algorithm. Different demographic MDS datasets have been tested, and different studies have proposed the integration of different genes into their prognostic algorithms. In a European study done by Haferlach et al., 14 genes (ASXL1, CBL, ETV6, EZH2, KRAS, LAMB4, NF1, NPM1, NRAS, PRPF8, RUNX1, STAG2, TET2 and TP53) were shortlisted to stratify MDS patients into four risk groups (low, intermediate, high, and very high risk) in combination with conventional scoring or as standalone scoring tools [13]. Similarly, Nazha et al. incorporated four genes (EZH2, SF3B1, and TP53) into their modified IPSS-R scoring system and achieved a significant improvement in the concordance index (C-index). Regardless of patient initial or subsequent therapies, the integration of mutation data also provides a dynamic platform for disease prediction [14]. For Asian MDS patients, Gu et al. proposed the mutation combined with the revised IPSS-R, namely MIPSS-R, taking into account the number of mutations and presence of SF3B1 mutations. Upon risk level adjustment, $39 \%$ of patients achieved better clinical outcomes for receiving other treatment regimens following MIPSS-R in comparison with following the conventional IPSS-R [15]. More recently, MDS has been classified into eight distinct genomic subgroups based on their mutational and cytogenetic profiles, Group 0: MDS without specific genomic profiles; Group 1: MDS with SF3B1 mutations and co-existing mutations (ASXL1 and RUNX1); Group 2: MDS with TP53 mutations and/or complex karyotype; Group 3: MDS with SRSF2 and concomitant TET2 mutations; Group 4: MDS with U2AF1 mutations associated with deletion of chromosome 20q, and/or abnormalities of chromosome 7; Group 5: MDS with SFSF2 mutations and co-existing mutations in other genes (ASXL1, RUNX1, IDH2, and $E Z H 2$ ); Group 6: MDS with isolated SF3B1 mutations (or associated with mutations of clonal hematopoiesis and/or JAK/STAT pathways genes); and Group 7: MDS with AML-like mutation patterns (DNMT3A, NPM1, FLT3, IDH1, and RUNX1 genes) [16]. These genomic groups correlated with the demographics, clinical, and hematological features, pathological classification and the overall survival [16].

The functional impact of mutations affecting signal transduction, transcriptional regulation, epigenetic regulation and RNA splicing molecules (Figure 1) will be discussed in details $[17,18]$.

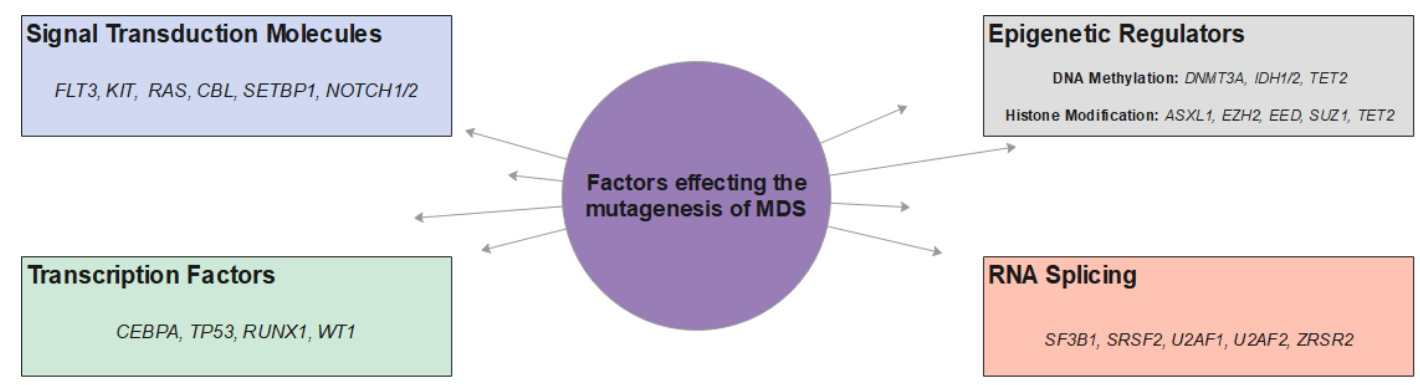

Figure 1. Molecular pathogenesis of MDS. Signal transduction molecules refer to gene mutations resulting in alteration to proliferative or apoptotic effects. Transcription factors and epigenetic regulators exert effects at both transcriptional and translational levels due to aberrations in RNA splicing, DNA methylation, and histone modification.

\subsection{Signaling Molecules and Pathways}

2.1.1. FLT3

The fms-like-tyrosine kinase III (FLT3) is a transmembrane tyrosine kinase, highly expressed on hematopoietic progenitor cell surfaces and is crucial for the development of hematopoietic stem cells (HSC) and progenitor cells [19]. This signaling pathway, stimulated by FLT3, regulates cellular processes such as cell division, survival, and growth in hematopoietic progenitor cells. FLT3 mutations reported in MDS are mostly internal tandem repeat (FLT3-ITD) located on exon 14 or 15 of chromosome 13q12 encoding the 
juxtamembrane domain, or, less commonly, a single point mutation of the tyrosine kinase domain (TKD) [20]. FLT3 mutations are well documented in AML with a prevalence of 30\% but FLT3 mutations occur at a much lower rate $(\sim 6 \%)$ in MDS [20-22]. Patients who carry FLT3 mutations are usually presented with a more adverse clinical course with a high risk of leukemic transformation [23]. FLT3 mutation is more common in younger patients and MDS with excess blast-1 or excess blast-2 (MDS-EB-1 or MDS-EB-2) [24]. FLT3 mutations lead to constitutive activation of FLT3 and downstream STAT5 signaling pathways. Exome sequencing done by Kim et al. revealed that the acquisition of FLT3 mutations in HSCs or hematopoietic progenitor cells (HPC) can drive the formation of leukemic stem cells (LSC) [25]. It was proposed that mutation acquisition can originate from the immature hematopoietic compartment, resulting in the accumulation of non-self-renewing blasts, which inevitably promote the transformation into AML $[26,27]$.

\subsubsection{KIT}

c-KIT proto-oncogene encodes a type III tyrosine kinase (KIT) is also known as CD117, and it is a mast/stem cell growth factor receptor (SCFR) influencing HSC survival, proliferation, and differentiation into the hematopoietic lineages $[9,28]$. There are three major protein domains involved in activities of KIT and downstream activation of PI3Kinase, Ras, and MAPK signaling. They are the extracellular membrane domain (EM) at exon 8, the juxta-membrane domain at exon 11, and the tyrosine kinase domain (activation loop) at exon 17. Gain-of-function mutations of these domains have been reported in other malignancies and some are also found in MDS patients [28,29]. KIT mutations are predominantly observed in patients with MDS-EB-1, MDS-EB-2, and secondary AML [29]. Among these mutations, most are gain-of-function mutations leading to ligand-independent activation of the KIT signaling, such as the D816V or D816Y of the tyrosine kinase domain.

These pathogenic mutations are likely associated with upregulation of KIT expression at the transcript and protein levels, observed in MDS patients, and the overexpression is more noticeable in patients with MDS-EB-1, MDS-EB-2, and secondary AML. In vitro studies have further shown that KIT expression can be induced by interleukin-3 (IL-3) and erythropoietin (EPO), with or without stem cell factor (SCF) expression on cell isolated from MDS patients [30]. In fact, depletion of KIT with humanized monoclonal antibody ablates the MDS HSCs in both LR- and HR-MDS xenograft models. Yet this also permits the subsequent engraftment of healthy HSCs, which is evident by robust engraftment of human B-cells and T-cells post-depletion of KIT. This confirms the stem cell's regulative property of KIT in MDS and AML, and hence the oncogenic property of KIT mutations [31].

\subsubsection{RAS}

RAS proteins are encoded by three proto-oncogenes (H-RAS, K-RAS, and N-RAS) that regulate differentiation and growth of many cell types, including myeloid cells. $R A S$ proteins are membrane-associated GTPases that regulate serine or threonine kinases of the MAP kinase cascade and mutations of RAS often constitutively activate RAS/MEK and RAS/PI3K signaling by accumulating intercellular RAS GTP [32]. Large scale studies have consistently reported RAS signaling deregulation due to mutations of RAS genes in MDS. RAS mutations are detected at an overall rate of $3-5 \%$ with $N-R A S$ genes being the most frequently mutated and K-RAS accounting for the remaining RAS mutations [13,32]. $N-R A S$ mutations at codon 12 account for $55 \%$ of all RAS mutations followed by $N-R A S$ mutations at codons 31 and 61 (12\% each) and K-RAS mutation at codon 12 (21\%) [33]. Patients with $R A S$ mutations also show higher white cell count and bone marrow blast percentage. Although the frequency of RAS mutations in MDS is much lower than that in CMML or AML, mutations of RAS in MDS patients, in particular N-RAS, have been found associated with shorter survival and higher risk of transformation into AML [33-35]. 


\subsubsection{CBL}

CBL plays an important role in tyrosine kinase signaling. CBL can activate signaling complexes and positively regulates downstream signal transduction components [36]. However, $C B L$ can also negatively regulate tyrosine phosphorylation through controlling the ring domain and tyrosine-kinase-binding (TKB) domain to induce ubiquitination. CBL also promotes E3 ligase catalytic activity on lysine residue in substrate proteins. As a result, lysine ubiquitination triggers proteasomal degradation and recycling in endosomes [37]. CBL controls protein degradation of several important proteins in myeloid neoplasms, including c-Kit, FLT3, and STAT5, which STAT5 is a key downstream component of the $J A K 2$ signaling. Not surprisingly, CBL mutations have been reported in $10 \%$ of patients with MDS/myeloproliferative neoplasm (MPN) overlap syndrome and these patients display clinical features such as splenomegaly, monocytosis, and anemia [38,39]. In MDS/MPN overlap syndrome, Sanada et al. also discovered a $C B L$ gain-of-function mutation can contribute to loss of the ubiquitin E3 ligase activity, thereby prohibiting ubiquitin-mediated degradation of tyrosine kinases, resulting in constitutive activation of tyrosine kinase signaling. Moreover, they have also reported $C B L$ mutations as acquired uniparental disomy (aUPD) in 31.5\% of the patients studied, and it is more common in MDS/MPN than MDS patients, where both copies of a chromosome pair or parts of chromosomes originated from a single parent [36]. Conventionally, aUPD is a mechanism by which pathogenetic mutations in cancer may be reduced to homozygosity. This process is typically described in loss-of-function mutations but is rarely reported in gain-of-function mutations. Therefore, this postulation provides novel insight on how the gain of oncoprotein resembles the loss of tumor suppressive gene [37].

\subsubsection{SETBP1}

SETBP1 gene is localized to chromosome 18q21.1 which encodes SET binding protein 1 and binds with SET nuclear oncoprotein to form a heterodimer and this complex suppresses SET from proteasomal degradation and downstream activity of tumor suppressor protein phosphatase type 2A (PP2A) [40,41]. Makishima et al. showed that SETBP1 mutation can affect tumor formation [40,42,43]. In MDS, multiple studies have reported SETBP1 mutations and the hotpot mutations localizes to codon 858-871. Changes like D868N, E858K and G870S belong to the SKI homologous region are predicted to be responsible for altering binding to SET [44]. While the mutation frequency varies from $2 \%$ to as high as $50 \%$ and is more commonly observed in LR-MDS, meta-analysis has shown that patients with SETBP1 mutation have significantly shorter survival. Thol et al. further reported a significantly higher rate of relapse within one year, and Shou et al. further showed that SETBP1 mutation is associated with poor prognosis in patients with MDS and CMML [8,44-49]. These mutations are somatic gain-of-function mutations associated with $-7 / \operatorname{del}(7 \mathrm{q})$ and are also enriched in patients with ASXL1 mutations as concurrent mutation, conferring a higher risk of transformation into AML [48]. In terms of function, these mutations, especially D868N and G870S, are proven to be pathogenic, as they suppress self-ubiquitination, hence inhibiting self-degradation and eventually leading to impaired apoptosis and differentiation.

In vitro studies have shown the increased clonal expansion can be further enhanced with additional ASXL1 mutation, and ASXL1 mutation shows a significantly higher rate of co-mutation with SETBP1 in patients $[48,50]$. This increases expression of mutant SETBP1 oncoprotein that favors the transformation of MDS cells into AML. One of the downstream targets of these mutants involved in MDS pathogenesis is the repression of TGF- $\beta$ signaling. Several lysine residues on histone $\mathrm{H} 3$ and $\mathrm{H} 4$ around the promoter regions of multiple TGF- $\beta$ pathway genes undergo aberrantly reduced acetylation. The dysregulated TGF- $\beta$ signaling in double mutant mice also shows higher engraftment, dysfunctional differentiation and uncontrolled cell cycle. However, these abnormalities are reversible using the HDAC inhibitor Vorinostat [51]. 


\subsection{6. $\mathrm{NOTCH} 1 / 2$}

NOTCH1/2 is a highly conserved cell surface signal transducer that regulates developmental and cell fate. In particular, NOTCH receptors are expressed by early HSC whereas NOTCH ligands are expressed by bone marrow stromal cells. Collectively, this forms a microenvironment providing the signal required for progenitor differentiation and proliferation [52]. The involvement of NOTCH dysregulation in MDS involves the dysplastic microenvironment with a suppressed NOTCH signaling activity followed by downregulation of delta-like-1 (DLK-1), which is an early adipogenic cell fate inhibitor. This causes an impaired colony-forming unit fibroblast in vitro, and this potentially contributes to a biased adipogenic differentiation of bone marrow stromal cells, also observed in bone marrow isolated from MDS patients [53].

In addition to impaired bone marrow microenvironment, NOTCH1-mediated suppression also contribute to HSC inadequate differentiation into progenitor subpopulations MPP3 (myeloid) and MPP4 (lymphoid), leading to dysplasia and selective clonal expansion in a murine model. During leukemic transformation or under cellular stress, NOTCH1mediated signaling is suppressed and the differentiation capacity of lymphoid MPP4 into mature lymphocytes is suppressed. MPP4 also diverges and contributes to myeloid cell expansion alongside with activated myeloid MPP3, leading to the accumulation of myeloid blast cells [54]. Therefore, it is not surprising that the loss-of-function mutation of $\mathrm{NOTCH}$ signaling genes could contribute to MDS and AML transformation.

In fact, NOTCH1/2 mutations have been reported at a frequency of $<5 \%$ in MDS and $12 \%$ in AML patients, but the direct evidence of NOTCH1/2 mutation implicated in MDS is limited $[8,55,56]$. Despite there being no significant correlation of NOTCH1/2 mutation with IPSS-R, NOTCH1 mutation is preferentially observed in HR-MDS [8]. With the postulation that MDS cells are subjected to apoptosis hence cytopenia is at least partially attributed to NOTCH signaling, Fu et al. performed in vitro studies by stimulating primary MDS cells with recombinant NOTCH ligand, hypothesizing that $\mathrm{NOTCH}$ signaling activation would suppress apoptosis. However, their results indicated that NOTCH ligands do not improve cytopenia features. The forced activation of NOTCH in vitro further decreases the formation of neutrophil colonies and increases the proportion of granulocyte-macrophage (GM) colonies and macrophage $(\mathrm{M})$ colonies, proposing that NOTCH signaling is dysregulated in dysplasia during MDS pathogenesis [57].

\subsubsection{Other Signal Transducers}

CSF3R is a transmembrane receptor for colony stimulating factor 3 (CSF3), mediating normal growth in myeloid progenitors. Under normal conditions, G-CSF binds to CSF3R for promoting growth and survival of myeloid precursor cells to neutrophils. CSF3R mutation is rarely seen in MDS. CSF3R mutations fall into two types: (1) nonsense or frameshift mutations resulting in premature truncation of cytoplasmic receptor and (2) point mutations at the extracellular domain of CSF3R [58]. It is shown that CSF3R is sensitive to JAK2 inhibitors, such as ruxolitinib [59]. Alternatively, truncated CSF3R truncated mutations are sensitive to SRC kinase inhibitors, such as dasatinib. Nevertheless, whether JAK2 or SRC inhibitors are of benefit to patients with CSF3R mutations remains to be investigated, since the majority of studies conducted regarding CSF3R are related to CML. The true incidence of this mutation appears to be much less in MDS, but it still presents as a significant mutation for the disease benchmark [60].

Janus kinase $2(J A K 2)$ is a non-receptor tyrosine kinase that regulates signaling pathways through $M P L, T p o R, E p o R$, etc. JAK2 is crucial for normal hematopoiesis and $J A K 2 V 617 F$ mutation is found in $2-5 \%$ of MDS cases. An increased incidence of thrombosis, hemorrhage, and fibrotic transformations are associated with the presence of the mutant allele in MDS. However, JAK2V617F mutation is less implicated in MDS in comparison with other myeloid malignancies, especially MPN, where JAK2V617F mutation is considered to be the driver mutation of MPN [61-63]. 


\subsection{Transcription Factors}

\subsubsection{TP53}

TP53 is a tumor suppressor gene located at chromosome 17p13.1, containing 11 exons, and is a transcription factor responsible for cell regulation and induction of apoptosis upon exposure to UV. TP53 is one of the most studied genes in cancers [64,65]. Somatic TP53 mutations are more frequently seen in HR-MDS, therapy related MDS, and MDS transformed leukemia. Complex karyotypes with deletions of chromosome 5, 7, and 17 (i.e., TP53) show a strong correlation with poor risk IPSS with morphological features, such as increased blast cell percentage and thrombocytopenia [66]. Deletion of chromosome $5 q$ results in the loss of a "commonly deleted region" (CDR), which comprises 41 genes, including RPS14, and haploinsufficiency of RPS14 is associated with erythroid failure in MDS [67]. Another gene that is closely regulated with TP53 is the Murine Double Minute-2 (MDM2). Under normal conditions, MDM2 is free to bind p53 and the binding of MDM2 with p53 triggers p53 ubiquitination and subsequent degradation.

Cytotoxic stress can activate the phosphorylation of both MDM2 and p53 via the ATM-Chk1 or ATM-Chk2 axes. This promotes a range of post-translational modifications of MDM2, including acetylation, methylation, and SUMOylation, which in turn contribute to p53 accumulation. The abnormal accumulation of p53 leads to cell cycle arrest, impaired DNA repairs, senescence, and apoptosis $[68,69]$. TP53 defects adversely influence MDS clinical outcome and the treatment response rate, such as resistances to HMA. Therefore, new therapeutic approaches, such as immune checkpoint inhibitions, are being developed for these patients, which will be reviewed in the later sections (Section 4) of this review [64].

Clonal evolution analysis of TP53 mutation in MDS has been described by da Silva Coelho et al. and both linear and branching patterns of evolutions were detected in the study [70]. In particular, TP53 mutation was found to be a branching clone as de novo mutation during treatment with lenalidomide, and TP53 is responsible for the drug resistance in these MDS patients [70]. Similarly, clonal evolution study done by Makishima et al. also proposed TP53 mutant clone as a namely "type 2 mutations". This group of clonal mutations are enriched in HR-MDS patients and is predicted with limited impact on AML transformation in comparison with "type 1 mutations", including FLT3, RAS, and IDH1/2, which harbor a significant impact on patient survival and AML progression. However, TP53 is also reported as a unique mutation, being mutually exclusive with other mutations, suggesting its potential role as a driver of mutation in MDS [71].

\subsubsection{RUNX1}

RUNX1 is a transcription factor that regulates HSC maturation into mature blood cells. RUNX1 is located on chromosome 21q22.12 and encodes an alpha subunit of the core-binding factor (CBE) complex [72]. This regulates transcription activities for key genes in differentiation, growth, and survival pathways. RUNX1 is commonly reported with somatic mutations and a majority of RUNX1 mutations found in MDS are small SNV or INDEL [73]. The mutation frequency of RUNX1 in MDS is 10\% and patients with RUNX1 mutations have higher neutrophil counts, a higher frequency of $-7 / 7 q$ deletion, and shorter overall survival [74].

This is concordant with the clonal sweeping model proposed by Makishima et al. regarding the disease progression of MDS from LR-MDS to HR-MDS, with RUNX1 mutation being one of the "type 2 mutations" [71]. Furthermore, RUNX1 mutant clones can be gradually replaced by the acquisition of another group of mutations, namely "type 1 mutations", as patients develop AML during the process of clonal evolution, in which "type 1 mutations" are associated with poorer survival and a faster rate of AML transformation [71]. In this study, two models of clonal evolution can be responsible for the mutation dynamics in different patients. They are clonal sweeping or linear evolution, of which linear evolution is the most common model and is characterized by the stepwise arising of a small subclone under the presence of a pre-existing dominant mutant clone and further expands during disease progression [71]. On the other hand, clonal sweeping refers to 
the pre-existence of multiple mutation clones, but one clone with the highest fitness (e.g., driver mutations) is selectively swept and dominates over other passenger mutations with less or no effects inside the tumor [75]. Regarding large genetic lesions involving ASXL1 mutation in MDS, some studies have proposed $-7 / 7 \mathrm{q}$ deletion as a secondary event to ASXL1 mutation, which can cause activation of the RTK-RAS pathway, promoting leukemic transformation $[74,76]$.

\subsubsection{WT1}

Wilms tumor 1 (WT1) is a tumor-suppressor gene coding for a zinc finger transcription factor located on chromosome 11p13, and was originally identified in Wilms' tumor [77,78]. WT1 mutations have been reported in $3-4 \%$ of MDS cases and sequencing studies have also shown that the presence of WT1 mutations favors MDS transformation into AML [79]. WT1 shows exceptionally low to absent expression in normal tissues while it is highly expressed in a wide range of malignant neoplasms with its key role being in regulating tumor cell proliferation. Around $60 \%$ of patients with MDS with single lineage dysplasia (MDS-SLD) overexpress WT1 in both bone marrow and peripheral blood samples, and WT1 expression level shows a good correlation with WHO clinical classifications and IPSS scores [80,81]. An in vivo study characterizing the hematologic phenotype of WT1 mutation demonstrated that, in the presence of the WT1 mutation, hematopoietic progenitor cells in mice significantly expand with an aggressive MDS/MPN phenotype, manifesting into anemia and erythroid dysplasia with a decreased survival [81].

\subsubsection{CEBPA}

$C E B P A$, which encodes $\mathrm{C} / \mathrm{EBP} \alpha$, is a CCAAT enhancer-binding protein that plays an important role in myelopoiesis, especially the differentiation from common myeloid progenitors (CMPs) into granulocyte-monocyte progenitors (GMPs) and eventually into mature granulocytes and monocytes. It possesses 14 enhancer regions and distinct enhancer combinations are active in different $C E B P A$-expressing tissues. Conformational studies of $3 \mathrm{D}$ genomic have shown that CEBPA localizes to a $170-\mathrm{kb}$ conserved topological-associated domain (TAD) on chromosome 19 and two enhancers located $+21 \mathrm{~kb}$ region located $3^{\prime}$ of the $C E B P A$ are myeloid specific with the highest promoter interaction in $C E B P A^{+}$myeloid cell lines in comparison with $C E B P A^{-}$lymphoid cell lines. This myeloid-specific chromatin conformation is also exclusively marked with active histone H3K27ac in differentiated neutrophils and monocytes. Moreover, the enhancers are occupied by the HSC specific transcription factors, including GATA, RUNX1, and PU1, evident by positive detection of these motifs on this specific region. Deleting one of the two enhancers in vivo thereby indirectly suppresses myeloid specific CEBPA and has a severe impact [82]. This causes demolished myelopoiesis and hence severe neutropenia and insensitivity to stimulation by G-CSF and GM-CSF, illustrating the functional importance of CEBPA in neutropenia, and hence infections in MDS [82,83]. In addition to distant enhancer dysregulation that causes suppressed CEBPA activity, in-frame but loss-of-function mutations of the CEBPA gene body itself are reported in MDS or MDS transformed AML. At a much lower rate than de novo AML ( $5.4 \%$ vs. $17.2 \%)$, and unlike AML which can have double mutations at both $\mathrm{N}$ - and C-terminus of $C / E B P \alpha$, MDS patients only have one of the mutations [84,85]. Mutations at $\mathrm{N}$-terminus suppress the activation capacity of $\mathrm{C} / \mathrm{EBP} \alpha$ by its direct binding to the target promoter or by its heterodimerization with $\mathrm{C} / \mathrm{EBP} \alpha$. On the other hand, mutations at the $\mathrm{C}$-terminus disrupt the basic zipper structure and part of the DNA binding domain, likely suppressing $\mathrm{C} / \mathrm{EBP} \alpha$ activity indirectly through disrupted interaction with other transcription factors, such as PU1 [84].

\subsubsection{Other Transcription Factors}

NPM1 (Nucleophosmin 1) is located on chromosome 5 (q35.1) and is associated with nucleolar ribonucleoprotein, which is responsible for the biogenesis of ribosomes, mRNA processing, and chromatin remodeling [86,87]. Mutations of NPM1 are detected in 20-30\% 
of AML cases, but are less frequent in MDS (9\%) [88,89]. NPM1 mutations are rare in MDS/MPN [90]. Bains et al. documented NPM1 mutations from a large cohort study in which the results were strongly associated with normal karyotypes and HR-MDS [88]. Due to the rarity of NPM1 mutation in MDS, there are no robust molecular or clinical data to further understand disease evolution in NPM1-mutated MDS.

\subsection{RNA Splicing}

In studies applying exome sequencing and targeted sequencing in MDS, it has been revealed that multiple RNA splicing mutations are implicated in its pathogenesis [91]. In normal cells, RNA splicing machinery begins with the pre-messenger RNA (pre-mRNA) intron removal and fusion of exons to form a mature mRNA. Spliceosomes are used to fuse $5^{\prime}$-mRNA splice site upstream exon to $3^{\prime}$-mRNA splice sites. They consist of the assembly of five small nuclear ribonucleoproteins (snRNPs) via their sequential binding to the pre-mRNA; hence, leading to the initiation of RNA splicing. This is achieved through the recognition of the $5^{\prime}$-mRNA splice site by $\mathrm{U} 1$ snRNP while the $3^{\prime}$ site is recognized by the U2-auxiliary factor (U2AF) [92,93]. The U2AF protein consists of a U2AF35 (U2AF1) subunit and a U2AF65 (U2AF2) subunit. U2AF protein binds to SF3B1 through a splicing factor (SF1) to form a heterodimer complex [94]. The U2AF35/U2AF65 heterodimer has a high affinity for ZRSR2 (Zinc finger RNA binding motif and serine/arginine rich 2) and SRSF2 (serine/arginine rich splicing factor), which binds to the polypyrimidine tract located at the $3^{\prime}$ splice site. SRSF2 involves the removal of introns from the primary transcript and is responsible for influencing patterns for alternate splicing. Any alterations to the spliceosome complex can result in a change in splicing specificity, leading to alternative splicing outcomes (Figure 2) $[95,96]$.
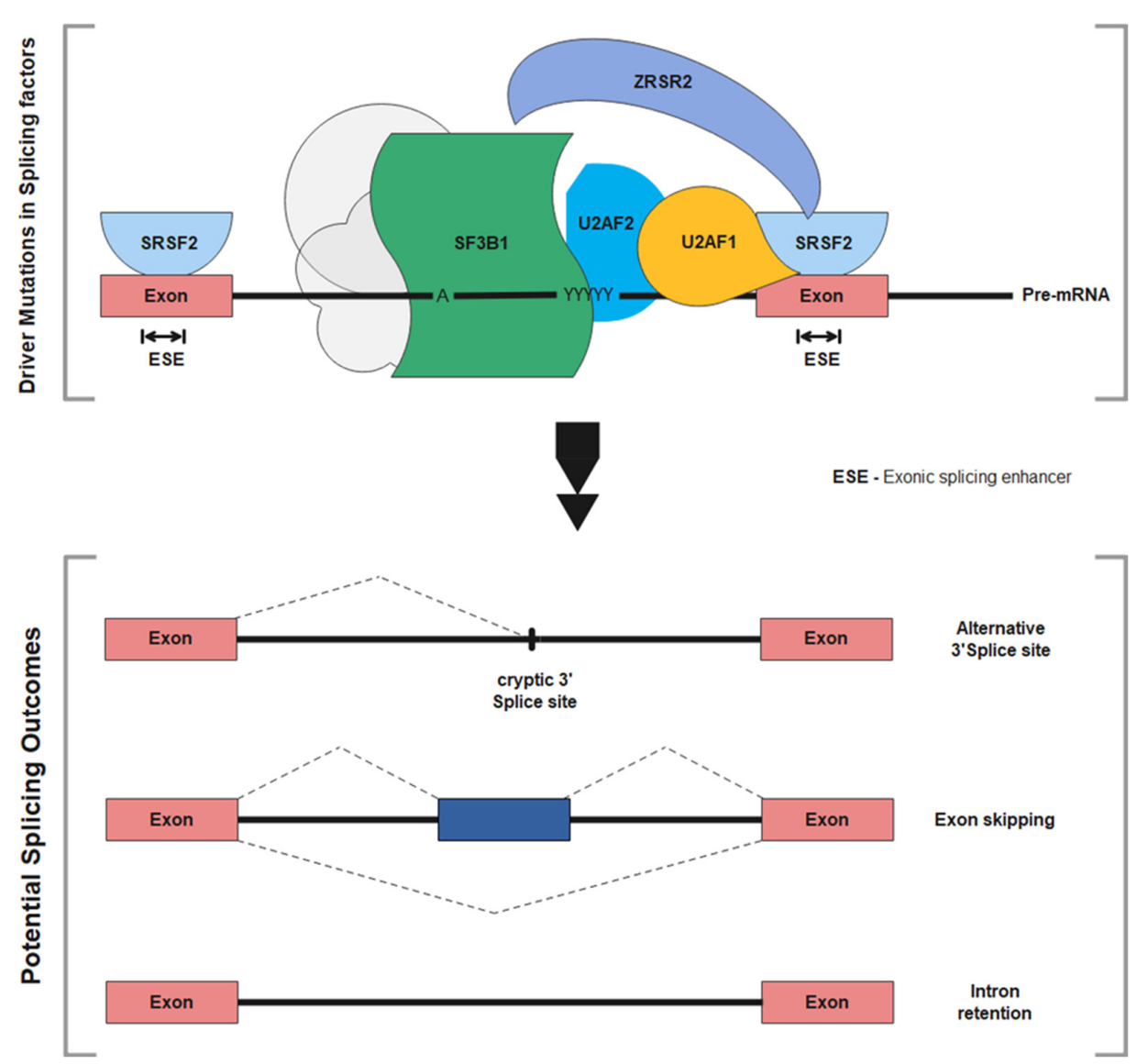

Figure 2. Driver mutations in splicing factors. The diagram shows key driver mutations in splicing factors in myelodysplastic syndrome and their potential splicing outcomes if one or more of these splicing factors are mutated. 
In MDS, concurrent spliceosome gene mutations, such as SRSF2 and SF3B1, are associated with HR-MDS, higher marrow blast percentage, and dysregulations of RNA splicing and DNA methylation pathways [13]. Splicing factor mutations at $3^{\prime}$ mRNA splice sites are common in MDS and around 60\% of MDS cases harbor mutations related to splicing factors. Frequently mutated splicing genes amongst MDS patients include SRSF2 $(\sim 12.4 \%)$. Another $20 \%$ of MDS patients carry multiple mutations, such as U2AF35, U2AF65, SF3B1, and ZRSF2 [97,98]. In particular, functional studies of U2AF35 mutation with other splicing factors have shown that splicing impairment, including intron retentions, induces mRNA splicing pathways and eventually growth impairment [99]. The SRSF2 mutation clusters around hotspot residue Pro95 are associated with epigenetic TET2 mutations [97]. SF3B1 mutations have been reported as a potential initiating event in defining sideroblastic anemia $[11,100]$. Computational analysis shows recurrent driver mutations, such as SF3B1, are associated with 5q deletion (del(5q)) in patients with MDS-RARS [100]. SF3B1 mutations are found in $68 \%$ and $81 \%$ in patients with MDS with ring sideroblasts and MDS/MPN with ring sideroblasts and thrombocytosis (MDS/MPN-RS-T), respectively. In vitro and in vivo experiments have also demonstrated the association of SF3B1 mutations with altered iron distribution in MDS patients ring sideroblasts and haploinsufficiency of SF3B1 is sufficient to cause ring sideroblasts transformation [98]. Woll et al. identified a high mean variant allele frequency (VAF) of SF3B1 (30.8\%), showing that the SF3B1 mutation is present in dominant MDS clones. Hence, this suggests the mutation itself originates from cells actively propagating in the MDS clones [101]. Moreover, SF3B1 mutation in MDS patients is often associated with alternative splicing of $S L C 25 A 37$, a crucial importer for iron in mitochondria [102]. Based on single cell clonogenic data, it has been proposed that a sequential acquisition of genetic lesions with SF3B1 in one of the mutated major clones at the early stages of MDS is implicated for subsequent AML transformation [103].

Mian et al. demonstrated that SF3B1 mutations in MDS with ring sideroblast can arise from HSCs during subclonal evolutions during disease pathogenesis [103]. Clonal analysis reveals the MDS mutational architecture displays an overall dominance of the SF3B1 mutation in primary CD34 ${ }^{+}$bone marrow, hemogenic endothelial cells (HEC), and Long Term culture initiating cells (LTC) [103]. For the functional impact of SRSF2 mutation in MDS, Kim et al. reported that SRSF2 mutation is associated with alternative splicing of epigenetic regulator EZH2. This induces a nonsense-mediated decay of EZH2 transcript, eventually impairing HSC differentiation. In vitro experiments rescuing intact $E Z H 2$, on the other hand, can restore the hematopoietic defects induced by mutant SRSF2, suggesting the crosstalk of compound mutations of different groups of genes in MDS pathogenesis [104]. Moreover, patients with splicing factor mutations alone have been reported to have better overall survival than those with additional mutations, such as cell signaling/transcriptional regulator, epigenetic modifiers, or other members of the splicing machinery [105].

\subsection{Epigenetic Dysregulation-DNA Methylation}

Demethylation of the cancer genome is the principal rationale of using HMA in myeloid malignancies. CpG methylation within gene promoters is a major epigenetic transcriptional silencing mechanism that is frequently dysregulated. In particular, transcriptional inactivation involving DNA methylation is primarily attributed to the methylation of $\mathrm{CpG}$ dinucleotides at the promoter region and gene bodies. This regulatory machinery is strictly regulated by DNA-methyltransferases (DNMTs), ten eleven translocations (TET) enzymes, and isocitrate dehydrogenases (IDHs) $[106,107]$. DNMT3A enzymatically adds a methyl group to $5^{\prime}$ cytosine at the CPG dinucleotide resulting in DNA methylation while the removal of the methyl group can be mediated by TET family proteins during demethylation [108]. TET2 plays a pivotal role in the oxidation of 5-methylcytosine (5mC) to 5-hydroxymethylcytosine (5hmC). In the citric acid cycle, IDH1/2 normally catalyzes isocitrate to $\alpha$-ketoglutarate $(\alpha-\mathrm{kg})$ while TET2 relies on $\alpha-\mathrm{kg}$ to function normally. When $\mathrm{IDH}$ mutation occurs, it gains an additional function to produce 2-hydroxyglutrate (2-HG) 
which inhibits the TET family proteins directly. IDHs mutations (e.g., at arginine 132 amino acid) are associated with elevated serum levels of 2-HG enantiomers (D-2-HG) in MDS patients, resulting in a reduction of $5 \mathrm{hmC}$ levels, and eventually hypermethylation (Figure 3) [109,110]. IDH1/2 mutations are present in approximately $5-12 \%$ of MDS patients with $I D H 2$ mutations occurring at a higher frequency than IDH1 [111]. Despite IDH1/2 has a lower incidence in MDS compared to AML, its occurrence increases over time with disease progression [111]. Other studies have shown early driver mutations in epigenetic modifiers can have co-mutation with spliceosomes genes, e.g., mutation of IDH2, EZH2 can couple with mutations of SF3B1, U2AF1, RUNX1, and STAG2, to dictate disease evolution with distinct clinical phenotypes in MDS [62,112].

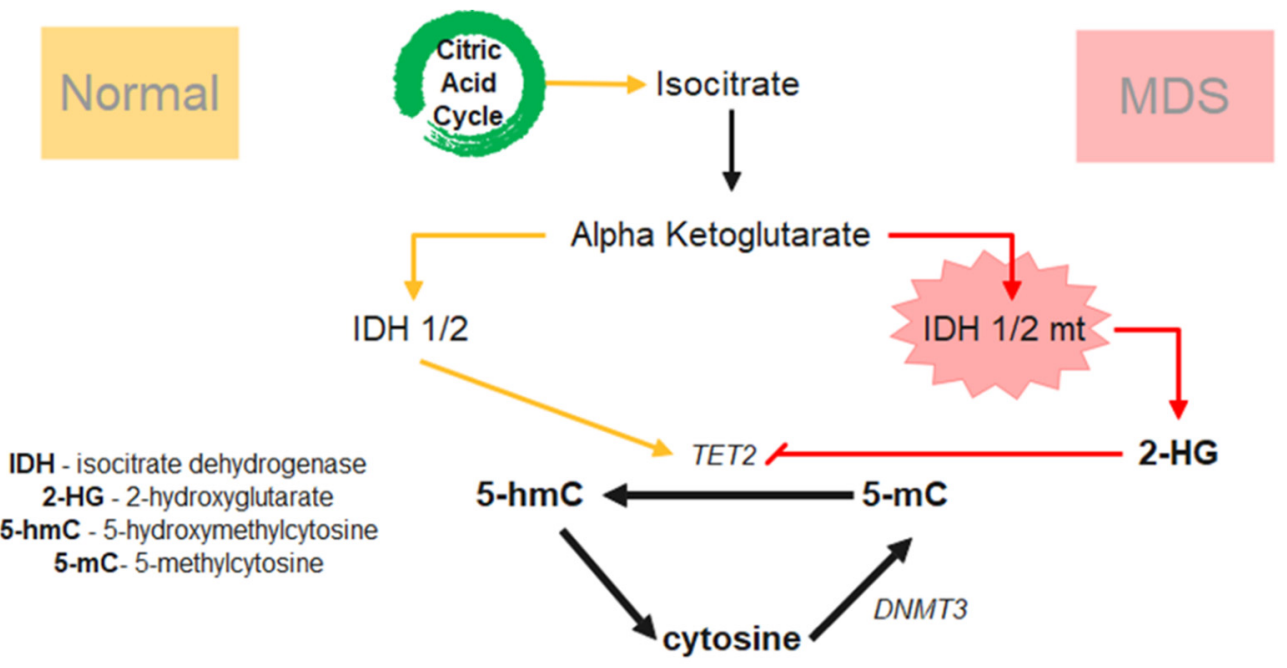

Figure 3. Mechanisms of DNA methylation under epigenetic dysregulation in MDS. Under normal circumstances, IDH1/2 promotes the TET2 genes to perform the conversion of 5-mC to 5-hMC, triggering DNA methylation. However, IDH1/2 mutations are often seen in MDS causing the inhibition of TET2, resulting in global hypomethylation but loci-specific hypermethylation.

In MDS, mutations of these epigenetic modifiers and spliceosomes are found to be associated with inflammasome signaling activation. This is evidenced by the finding that epigenetic dysregulation is associated with activation of NOD-like receptor protein 3 (NLRP3) inflammasomes, followed by increasing levels of damage-associated molecular patterns (DAMPs) in MDS. DAMPs are high mobility group proteins, such as B1 and alarmin S100 proteins, which are responsible for sensing the presence of Toll-like receptors (TLRs). Increased levels of DAMPs and NLRP3 inflammasomes activation are enriched in LR-MDS patients [113-116]. MDS stem cells are specifically susceptible to DAMPs because they overexpress TLRs, as well as signal transducers, such as IRAK1 and TRAF6 [117,118]. These mutations increase the production of pro-inflammatory cytokines, such as IL- 6 and Type 1 IFN- $\alpha$. The dysregulated inflammasome with S100A9 and NLRP3 having a role to play activates $\beta$-catenin signaling, eventually resulting in pyroptosis $[113,119,120]$. Ligation of S100A9 with TLR4 induces NF-kB-mediated transcription of pro-inflammatory cytokines, including pro-interleukins IL-1 $\beta$, IL-18, and other inflammasome components [112]. The active NLRP3 inflammasome directs caspase-1-dependent conversion of pro-IL-1 $\beta$ /IL-18 into active forms resulting in pyroptosis $[112,113]$.

\subsection{Epigenetic Dysregulation-Histone Modification}

\subsubsection{EZH2, EED and SUZ12}

Alterations in epigenetic processes, including DNA methylation and histone modifications, are well-known pathological events in MDS that self-renewal of HSC compartment is often dysregulated. Enhancer of the Zeste Homolog 2 (EZH2) is a protein subunit of the poly-comb repressive complex 2 (PRC2). PRC2 catalyzes methylation of histone $\mathrm{H} 3$ 
lysine 27 methyltransferases (H3K27me), hence maintaining transcriptional repression of genes involved with cell fate decisions. In MDS, EZH2 mutations can result in a malformed PCR2 complex hence loss-of-function of H3K27me and impede normal function of the other two subunits EED and SUZ1 (Figure 4). While mutation of EED and SUZ12 in MDS are rare $(<1 \%), E Z H 2$ mutation is common and is associated with poor prognosis in MDS. In addition to male predominance of $E Z H 2$ mutation in MDS, both EZH2 mutation and loss of EZH2 protein expression independently correlate with inferior survival and R-IPSS score $[121,122]$. Despite the fact that survival is not affected in vivo, murine models with EZH2 double knockout develops myelodysplastic phenotypes evident by morphologic dysplasia of HSC, cytopenia with occasional thrombocytosis that resembles MDS/MPN overlap syndrome [123].

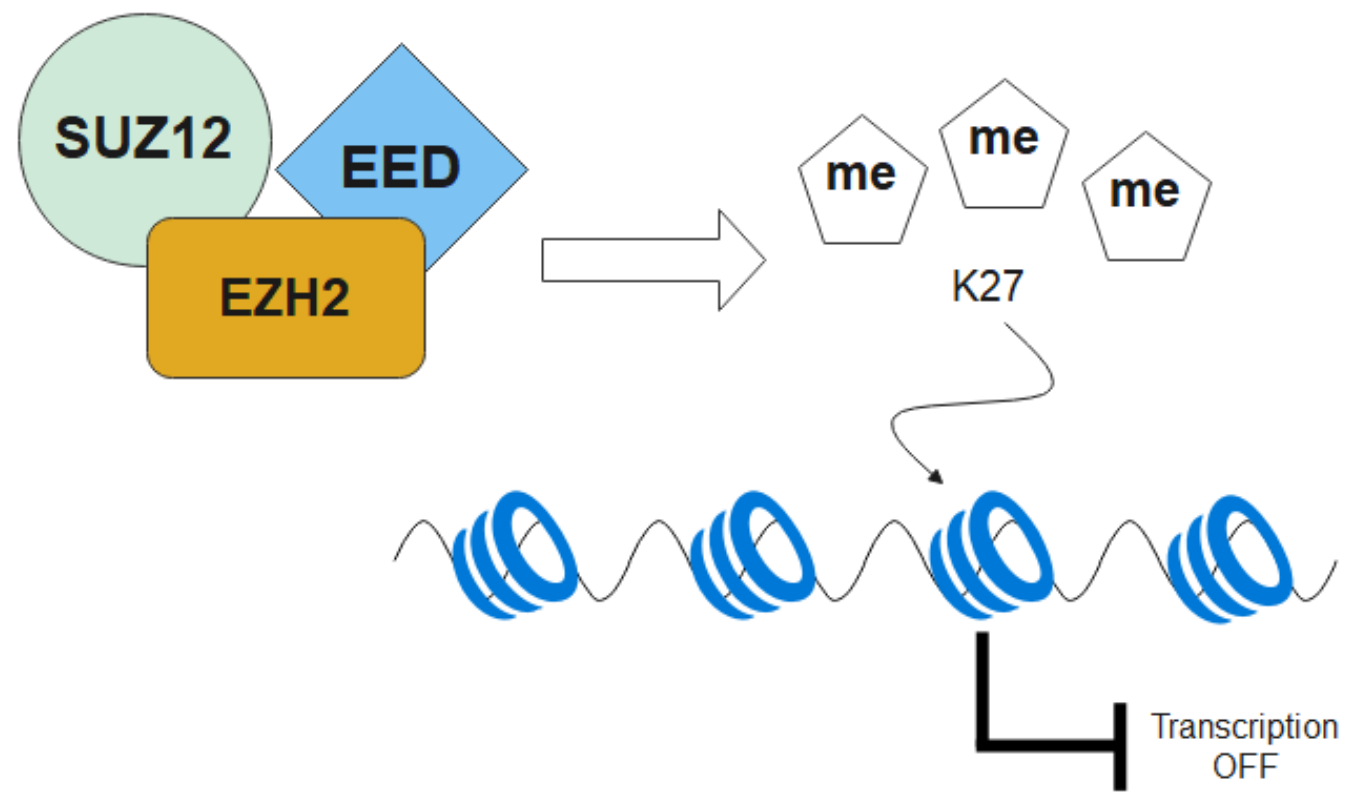

Figure 4. Mechanism of histone modification in MDS. Under normal circumstances, the PRC2 complex promotes methylation by regulating H3K27me resulting in transcriptional activation. However, loss-of-function mutation of EZH2 causes PCR2 to malfunction resulting in HSC disorders.

\subsubsection{ASXL1 and TET2}

ASXL1 plays a role in deubiquitinating histone H2A lysine 119 (H2AK119) through the recruitment of the PRC2 complex. ASXL1 mutations result in loss of protein function to promote myeloid transformation due to the absence of PRC2 mediated gene repression [124,125]. Approximately $80 \%$ of patients with MDS have one or more oncogenic mutations. These mutations include ASXL1 and TET2 at mutation frequencies of $\sim 15 \%$ and $\sim 22 \%$, respectively, and both are considered as representative mutations found in MDS [62,126,127]. The ASXL1 gene is localized on chromosome 20q11 and it is one of the frequently mutated genes with prognostic significance [128-130]. Some studies have reported ASXL1 mutation as a gain-of-function mutation that enhances acetylation of H3K122, and this triggers transcriptional activation of Fos and Prdm16 [9,131-133]. In contrast, multiple NGS and meta-analysis studies have reported that TET2 mutations do not possess any prognostic value $[134,135]$. TET2 promotes O-GlcNAc transferase (OGT) activity by forming the TET2-OGT complex to promote enrichment of H3K4me3, contributing to increased transcriptional activity. Therefore, TET2 mutation causes suppression of OGT activity which directly blocks H3K4me3, resulting in decrease transcriptional activity [134]. Moreover, loss-of-function mutation of TET2 results in a predominance of $5 \mathrm{mC}$ in DNA [134]. The accumulation of $5 \mathrm{mC}$ can promote B-cell development and function resulting in activation of innate immune systems, as well as the disruption of DNA methylation 
homeostasis [136,137]. Despite there being controversies in the functional impact of TET2 mutations in MDS, it remains as an important epigenetic enzyme [10,134,135].

\section{Immune Dysregulation}

In MDS, a pro-tumor growth microenvironment and the pro-inflammatory signals provided by the immune cells are essential for its pathogenesis. Aberrant signaling pathways like TLR signaling are involved. In the following section, the interactions of adaptive and innate immunity in MDS pathogenesis will be outlined; in particular, immune checkpoint evasions and inflicted inflammation.

\subsection{Adaptive Immune Dysregulation}

The function of immune checkpoints is to regulate antigenic activities and selftolerance through co-stimulation or direct immune cell inhibition, but tumor cells can evade the tumor surveillance by overexpression of inhibitory proteins. In MDS, immune dysregulation causes autoimmune disease-like features. LR-MDS is characterized by autoimmune-mediated apoptosis, while HR-MDS is characterized by a clonal expansion of selected progenitor lineage [138]. The co-existence of selective cell proliferation and apoptosis of alternative clones complicates the disease pathogenesis. In LR-MDS or early MDS patients, apoptosis signaling is associated with multiple mechanisms: (1) activation of Fas signaling as a result of an increased level of pro-apoptotic cytokines (e.g., TGF- $\beta$, IFN- $\gamma$ and TNF- $\alpha$ ); (2) elevation of T-helper (Th) type 17; (3) dysfunctional B-cells; and (4) cytopenic regulatory T-cells (Treg) [139]. Kotsianidis et al. discovered that autoimmunity regulated by Treg is distinct between two MDS risk groups. In comparison with HR-MDS and normal hematopoiesis, $\mathrm{CD}^{+} \mathrm{CD}^{2} 5^{+} \mathrm{FOXP}^{+}$Treg cells are found dysfunctional and failed to home to bone marrow microenvironment due to downregulation of CXCR4. This leads to decreased self-tolerance hence autoimmunity by T-cells in the bone marrow [140]. This is supported by the additional study from Zou et al. which showed that $\mathrm{CD} 4^{+}$Th-cells are deficient rather than $\mathrm{CD}^{+}$cytotoxic cells. An increased percentage of quiescent memory $\mathrm{CD}^{+}$and $\mathrm{CD}^{+}$cells in the peripheral blood of MDS patients is also observed. Hence, a lower age-corrected ratio of $\mathrm{CD}^{+}: \mathrm{CD}^{+}$cells and a significant drop in proliferative index in both T-cell subpopulations have been observed in patients responding to immunosuppressive therapy [141].

While the major effector immune cells in the adaptive immune system lie with $\mathrm{CD} 8^{+}$ cytotoxic T-cells, major receptors involved in T-cell activation and suppression are grouped into co-stimulatory receptors and co-inhibitory receptors respectively. Co-stimulatory receptors include CD28, 4-1BB, C1D27, ICOS expressed on T-cells, and CD80 and CD86 expressed on antigen presenting cells [142]. On the other hand, co-inhibitory receptors include cytotoxic T-lymphocyte-associated-protein 4 (CTLA4) and programmed cell-death protein (PD1, also known as CD279) are predominantly expressed by T-cells $[143,144]$. Programmed cell death ligand 1 (PD-L1/CD274) and B7 are ligands of PD-1 and CTLA-4 respectively, which are expressed on antigen-presenting cells (APCs) [143]. The molecular interactions of PD-1/PD-L1 and CTLA-4/B7 axes suppress the immune response. This suppression of T-cell activity serves as an escape mechanism from immune surveillance in several hematological malignancies, including myeloid neoplasms [145,146].

In MDS, studies have shown that PD-1, PD-L1, and CTLA-4 are aberrantly upregulated in MDS patients [146,147]. Yang et al. reported the overexpression of PD-1 in MDS patients. Higher levels of PD-1 have been demonstrated in HR-MDS in comparison with LR-MDS patients [146]. Myeloid cells take advantage of these immune checkpoints by upregulating inhibitory ligands CD47, B7-1, B7-2, and PD-L1 [145,148]. MDS cells have demonstrated the ability to harness some immunosuppressive effects to facilitate their survival and proliferation. For example, T-cells have increased expression of immunoinhibitory receptors ligands CTLA4, ICOS, PD-1, and T-cell immunoglobulin mucin 3 (TIM-3, also known as CD366) found on MDS patients with treatment-refractory compared with healthy donors [149]. PD-1 and PD-L1 levels are also elevated in patients after 
treatment of HMAs or upon HMA failure, albeit discovering no significant association between the level of PD-1 expression in response to HMA [146].

In the context of TIM-3 dysregulation which is a distinct AML marker present predominantly on leukemic stem cells (LSCs), TIM3 is absent on normal HSCs [150-152]. However, its presence on MDS blasts cells is associated with disease progression and leukemic transformation, and this is evident by the upregulation of pro-proliferative or anti-apoptotic genes [151]. Galectin 9 (Gal-9), one of the ligands of TIM-3 receptor is found excessively expressed on myeloid-derived suppressor cells (MDSCs), exerting an inhibitory effect on immune and inflammatory reactions [153]. The TIM-3/Gal-9 pathway takes part in MDSC-induced T cell exhaustion [150-153]. It also activates NF- $\mathrm{kB}$ and $\beta$-catenin signaling and promotes self-renewal in TIM-3 ${ }^{+}$LSCs [154].

\subsection{Innate Immune Dysregulation}

Abnormal innate immunity associated inflammation also contribute to the physiopathogenesis of MDS. This is evident by overexpression of upregulation of immune related genes in hematopoietic stem or progenitor cells, including TLRs, CD14, and signaling proteins of the NF-KB and MAPK pathways $[120,155,156]$. As a result, these MDS stem cells increase the production of pro-inflammatory cytokines TNF- $\alpha$, IL-1, IL-8, and IL-6, contributing to inflammation in MDS. Despite there being a mild discrepancy in dominant TLR responsible for the autoimmune mediated inflammation, TLRs are elevated in CD $34^{+}$ MDS cells. TLR2 is likely responsible for the constitutive apoptosis, and LR-MDS is more prone to this phenomenon in comparison with HR-MDS [117,118,157].

In terms of immune cell, NK cells functions in both innate and adaptive immune response. Unlike early MDS, advanced MDS is characterized by dysfunctional natural killer (NK) cells, immune evasion coupled with increased Treg, therefore, expansion of anti-apoptotic neoplastic cell lineage [139,158-160]. The key receptors controlling selfrecognition by human NK cells are HLA class I-binding receptors, including the killer immunoglobulin-like receptor (KIR) family as well as the natural killer Group 2A (NKG2A) and leukocyte immunoglobulin-like receptor subfamily B member 1 (LILRB1, also known as LIR-1) [160]. Especially among HR-MDS patients, multiple reports have shown NK cells decreased expression of NKG2D and DNAM-1 [159,161,162]. Carlsten et al. further reported the loss of the potent anti-tumor property of NK cells in vitro and that these NK cells display impaired cytotoxicity towards CD $34^{+}$MDS blast cells, hence evading tumor surveillance.

For dendritic cells (DCs) and macrophages, which are both the major players in innate immunity, the tumor microenvironment is further complicated in response to the upregulation of proliferative cytokines. While DC is normally responsible for tumor recognition and antigen presentation, cytopenic DC in MDS patients has been reported and is predicted to be defective in activating Treg cells [163]. This finding is supported by recent in vitro studies of DCs isolated from MDS patients (MDS-RA and MDS-RARS) showing significantly lowered levels of both mature and immature DCs coupled with deprived antigen presenting ability to Treg [164]. Moreover, macrophages are found suppressed in MDS and this phenomenon is more profound in HR-MDS than LR-MDS [139]. In general, the macrophage is crucial for phagocytosing, hence clearing cellular debris from aborted differentiation of hematopoietic cells. However, TLR signaling is found to be activated in macrophages via TLR4 overexpression, contributing to inflammasome activation in MDS [155,165]. Han et al. also reported that monocyte-derived macrophages in LR-MDS or intermediate risk MDS patients are found to be reduced despite monocyte counts being higher than in normal individuals. Such suppressed macrophage populations are also inefficient in phagocytosis of abnormal MDS cell clones, producing a pro-tumor growth microenvironment in bone marrow [166].

Most notably, signal regulatory protein alpha (SIRP $\alpha)$, the ligand of CD47, is present on DC and macrophages [167]. With CD47 being a transmembrane protein expressed on the surface of tissue cells and myeloid leukemia cells, CD47 serves as a self-marker for host 
tissue recognition and evasion of immune response [168-170]. During a normal immune response to foreign antigens, expression of the inhibitory ligand CD47 modulates cells into anti-apoptosis and enhances the function of immune suppressor Treg, resulting in antigen-specific T-cell cytotoxicity. When inhibitory ligand expression is low, tumor cell apoptosis can occur and T-cell receptor (TCR) mediates cytolysis, induced by T-cells [171]. With CD47 expression being high in MDS LSCs of HR-MDS compared to those of LR-MDS, binding of CD47 to SIRP $\alpha$ prevents MDS cells from phagocytosis and hence promotes selected clonal expansion, contributing to a HR-MDS phenotype [168-170].

\section{Treatment of MDS}

\subsection{Hypomethylating Agents (HMA)}

The first generation of HMA was developed as conventional cytostatic therapy back in the 1960s [172]. The use of HMA drugs in MDS aims to restore the expression of tumor suppressive genes silenced by promotor hypermethylation $[173,174]$. The current generation of HMA drugs are AZA (5-azacytidine) and DEC (5-aza-2'-deoxycytidine). AZA is administered subcutaneously at a dose of $75 \mathrm{mg} / \mathrm{m}^{2}$ for 7 days every 28 days, and DEC is given intravenously at a dosage of $15 \mathrm{mg} / \mathrm{m}^{2}$ every $8 \mathrm{~h}$ for 3 days with repetition every 6 weeks. Both drugs have shown beneficial effects in MDS and have been approved by the US Food and Drug Administration (FDA) since 2004 and 2006, respectively [175,176]. A 5day regimen of DEC at $20 \mathrm{mg} / \mathrm{m}^{2}$ at a 28-days interval that allows easier administration was later approved by the FDA in 2010 as the clinical standard [173,174]. DEC has been reported to stimulate NK cell responsiveness to IL-2 stimulus while AZA can impair NK cell activities through IFN- $\gamma$ modulation [177]. Allogeneic immune reactions of donor lymphocyte infusions by DC have also been reported to increase through HMA treatment [178]. In contrast, the bone marrow microenvironment, such as mesenchymal stromal cells (MSC), was found suppressed upon HMA treatment in MDS patients [179].

There are studies that have demonstrated the immunomodulatory effects of HMA in MDS. Gomez et al. evaluated the hematopoietic architectures of MDS cells before and after HMA treatments and discovered distinct sub-populations, being CD $34^{+}$and CD38 ${ }^{+}$, upon disease progression [180]. CD38 expression on CD8 ${ }^{+} \mathrm{T}$-cells was found to have a negative correlation with IFN- $\gamma$ and abundance of $\mathrm{CD}^{+} \mathrm{T}$-cells after the introduction of HMA indicated decreased T-cell activity [181]. Another study demonstrated that a decrease in $\mathrm{CD}^{+}$cells is associated with the introduction of DEC with anti-PD1 treatment [182]. Early research has also shown the induction of Tregs via demethylation of $\mathrm{FOXP}_{3}$ promoter by HMA, this led to investigation of how HMA affects the functions of NK cells $[183,184]$.

The molecular mechanism of HMA comprises of cellular uptake, intracellular activation, nucleic acids incorporation, and DNMT inhibition resulting in DNA hypomethylation (Figure 5). The cellular uptake is regulated by two different transporters: (1) human concentrative nucleoside transporter (hCNT) for AZA intake, and (2) human equilibrative transporter (hENT) for DEC intake [185]. Enzymes catalyzing the rate limiting step are 1-uridine-cytidine kinase (UCK) and deoxycytidine kinase (DCK), which produce 5azacitidine-triphosphate (5-aza-CTP) from AZA and 5-aza-2'-deoxycytidine-triphosphate (5-aza-dCTP) from DEC, respectively. HMA is considered as an S-phase specific drugs due to its nature of incorporation into DNA during cell replication.

Upon intracellular activation, DEC exclusively incorporates into DNA only and AZA primarily incorporates into RNA. Meanwhile, $15-20 \%$ of AZA intake can be converted from 5-aza-CDP to 5-aza-dCDP through ribonecleotide reductase (RNR), which then can be integrated into the DNA. After a series of phosphorylation events give rise to the 5-aza-CTP and 5-aza-dCTP for AZA and DEC, respectively, which leads to incorporation of RNA and DNA resulting in irreversibly bind to maintenance DNMT1 resulting in degradation of DNMT1 and DNA de-methylation [179]. DNA demethylation can lead to the reactivation of abnormal silenced genes, involving multiple pathways, such as angiogenesis, apoptosis, differentiation, and DNA repair [179]. 


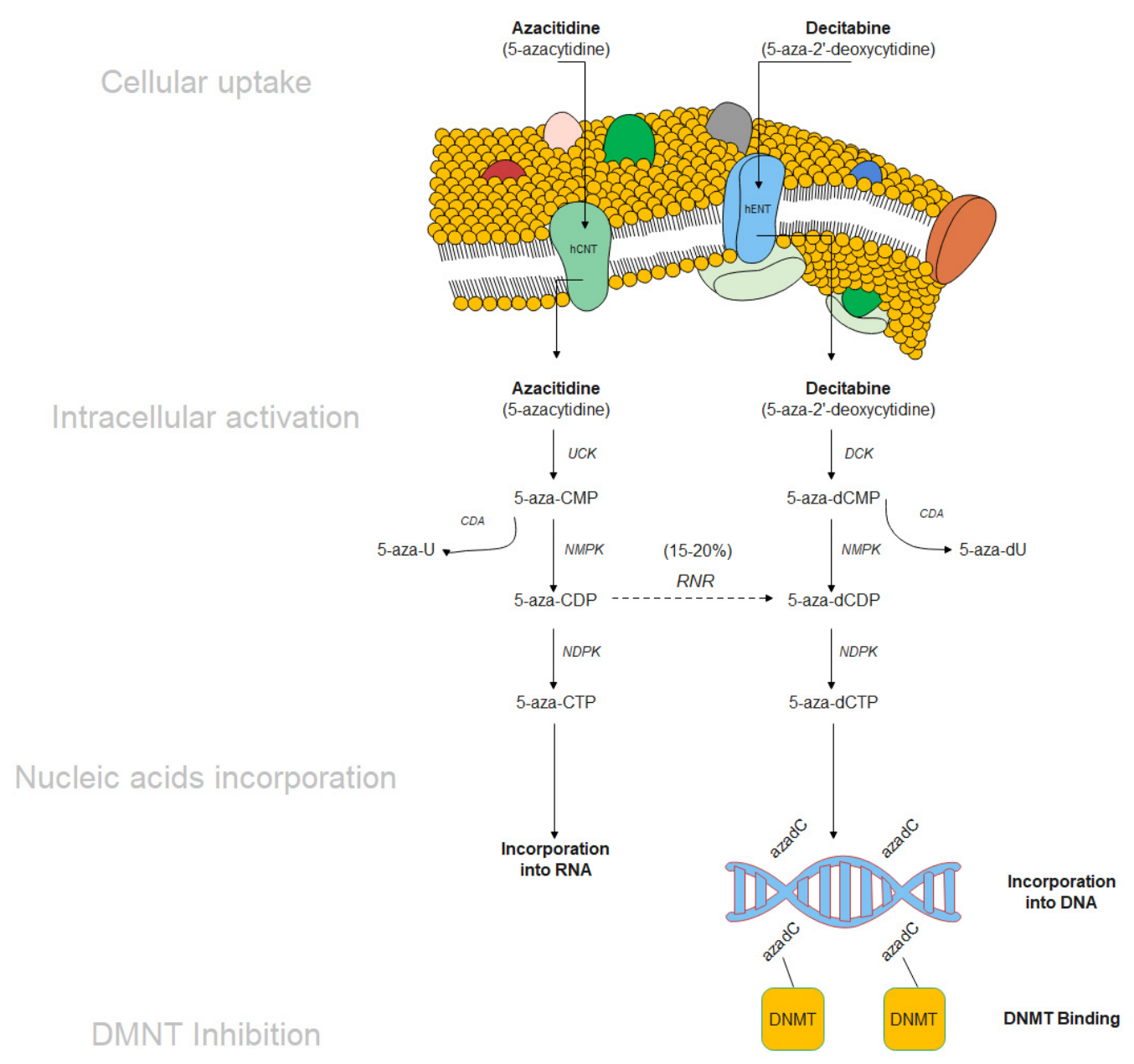

Figure 5. Schematic representation of AZA and DEC uptake and metabolism. UCK-uridine-cytidine kinase, DCK - deoxycytidine kinase, CDA—cytidine deaminase, NMPK—nucleoside monophosphate kinase, NDPK—nucleoside diphosphatase kinase, RNR—ribonucleotide reductase.

\subsection{Mechanisms of Resistance to Hypomethylating Agents}

In spite of the good initial treatment responses to HMA, 40\% of MDS patients will develop resistance to HMA $[179,186]$. There are two types of HMA resistance: primary resistance, which refers to a patient with no improvement after 4-6 cycles of treatment, and secondary resistance that refers to disease relapses after long-term treatment. Various studies have been performed to study primary and secondary HMA resistance. Qin et al. demonstrated that resistance to DEC in most cancer cell lines has downregulated genes involving in the uptake and activation of DEC, while they also noticed a high expression of cytidine deaminase (CDA) [186,187]. The loss of DCK and mutations of UCK2 can cause resistance to DEC and AZA, respectively. Unfortunately, pre-clinical evidence of HMA resistance in MDS is relatively unclear. For DEC resistance, MDS patients with primary resistance present a high CDA to DCK ratio resulting in the inactivation and decrease of 5 -aza-dCTP. In MDS patients with secondary resistance, upregulation of mutated DCK mRNA with suppressed activities of DEC. For AZA, a downregulation of UCK1 in MDS AZA resistant patients is reported but not $U C K 2$, postulating the two enzymes do not have identical relevance to AZA resistance [188-190].

In terms of immunomodulation during HMA resistance, there are studies that have demonstrated failed immune response being correlated with high expression of $P D-1$, $P D-L 1, P D-L 2$ and CTLA-4 in MDS. Treatment with DEC results in a dosage-dependent upregulation for these genes, and partial demethylation of PD-1 [146]. Ørskov et al. also demonstrated that demethylation of PD-1 promoter correlates with significantly inferior response rates during HMA treatment in MDS. They also reported that HMAs induce 
PD-1 expression on T cells in the MDS microenvironment, thereby impeding the immune response against the MDS blasts [191].

\subsection{Next Generation HMA—Strategies to Overcome HMA Resistance}

Although AZA and DEC currently remain standards of care in MDS, their short halflife and poor oral availability prompted persistent efforts for the development of novel HMAs and combinations [187]. CC-486, an oral formulation of AZA, was developed to enhance the ease of administration and dose adjustment [187]. In a study, MDS patients presented a reduction in DNA methylation induced by the current 7-day AZA regimens that was subsequently reversed towards the end of the cycle [192]. In contrast, persistent reduction of methylation was achieved by extended dosing of CC-486 for either 14 or 21 days [193]. The use of the 14- and 21-day regimens in patients with LR-MDS produced an encouraging overall response rate (ORR) of $38 \%$ alongside a tolerable safety profile. The most frequent grade 3-4 adverse events were neutropenia, anemia, and gastrointestinal disturbances [194]. In a placebo-controlled randomized phase III trial, CC-486 significantly enhanced red cells and platelet improvement rates at the cost of increased incidence of adverse events compared to placebo (90\% vs. 73\%) [195]. In spite of the higher infection-related mortality rate in the CC-486 arm in the first 56 days, the overall mortality rates remained similar between the two arms [196]. Alternative treatment may overcome adaptive responses due to repetitive use of HMA. Recent clinical trials have also explored novel HMAs along with combination therapy as potential strategies to overcome HMA resistance [195].

\subsubsection{Guadecitabine (SGI-110)}

Guadecitabine (SGI-110) is a dinucleotide of DEC and deoxyguanosine that is administered via subcutaneous injections [187]. A DEC analog is resistant to deamination by $\mathrm{CDA}$, and is hence more effective with easier administration given the less-frequent dosing requirements compared to AZA and DEC [197]. The prolonged duration of action of this agent can be accounted for by its resistance towards CDA mediated degradation [187]. A multicenter phase I study among relapse/refractory (R/R) AML and MDS patients highlighted its clinical efficacy, where $22 \%$ (2 out of 9) of MDS patients showed marrow complete responses [198]. A phase II study of guadecitabine in HR-MDS patients with AZA resistance demonstrated an ORR of $14.3 \%$ with significant improvement in survival among responders [199]. However, in the randomized phase III ASTRAL-3 trial, guadecitabine failed to improve the survival of previously treated MDS patients when compared to standard treatments [200]. This agent was generally well tolerated, with the most common grade 3 or above adverse events being febrile neutropenia, myelosuppression, and infections $[198,199]$.

\subsubsection{ASTX727}

ASTX727 is an orally available combination of DEC and CDA inhibitor cedazuridine. Its impressive activity is first elucidated in a multicenter phase I/II study among MDS and CMML patients, where non-inferiority of ASTX727 towards IV DEC is established, along with a CR rate of $18 \%$ and transfusion independence rate of $49 \%$ [201,202]. In the randomized phase III ASCERTAIN study among MDS patients, comparable demethylation activity and safety profiles between ASTX727 and IV DEC were demonstrated [195]. These satisfactory results have prompted FDA-approval of ASTX727 for previously treated and untreated, de novo and secondary MDS with specific FAB subtypes (RA, MDS-RARS, MDS-RAEB, and CMML) and IPSS scores (intermediate-1, intermediate-2, and high-risk) in 2020. ASTX727 has a favorable safety profile, with febrile neutropenia and infections being the most common serious adverse events [201-203]. 


\subsection{Targeted Therapy in Combination with Hypomethylating Agents}

Although HMA treatments have survival benefits and are the current standard of care, many MDS patients will not garner a response from therapy. For those who do respond, most responses are not durable, and the only hope for treatment is allo-HSCT. New therapies to combat HMA resistances are urgently needed. Several of these small molecules have demonstrated the ability to augment the response rates of HMA, including complete remission (CR) rates, in both the front line and refractory settings. Clinical trials of targeted therapy for MDS patients are mainly based on the safety and efficacy data demonstrated in AML patients. This section focuses on discussing the rationale and application of co-administration of targeted therapy and HMAs in MDS patients.

\subsubsection{BCL-2 Inhibitors}

Venetoclax, approved by the FDA, is a BCL-2 inhibitor that can be used in combination with HMAs in HR-MDS patients and has been reported to have a good therapeutic response in a case study as a monotherapy (ClinicalTrials.gov (accessed on 21 September 2021) Identifier: NCT02966782) [204]. It acts as a BH3 mimetic that impedes the binding of $\mathrm{BH} 3$ proteins to BCL-2, hence releasing pro-apoptotic BAK and BAX proteins $[205,206]$. This results in mitochondrial outer membrane permeabilization (MOMP) with the release of cytochrome $\mathrm{C}$ into the cytoplasm, leading to the formation of cytosolic apoptosome complex, caspase activation, and subsequent cellular apoptosis [207].

More importantly, dose optimization co-treatment of venetoclax and AZA could effectively spare hematopoiesis without affecting its ability to target malignant cells [208]. Encouraging results have been observed in clinical trials. A phase $1 \mathrm{~b}$ trial on treatmentnaïve HR-MDS patients demonstrated an ORR of $74 \%$ and progression-free survival (PFS) of $59 \%[209,210]$. This finding was further validated in another study that showed a compatible ORR with a majority of patients being bridged to allo-HSCT [211]. The phase 3 VERONA trial is currently underway to further assess the safety and efficacy of combination therapy (ClinicalTrials.gov Identifier: NCT04401748) [212]; however, it should be noted that cytotoxic effects might be aggravated by concomitant CYP3A4 inhibitors $[206,208]$. For instance, dose-adjustment of venetoclax is required with concomitant use of triazole, a frequently used CYP3A4-inhibiting anti-fungal in MDS patients [206]. In addition, granulopoiesis is particularly suppressed in combination therapy, febrile neutropenia is, therefore, a commonly exhibited adverse effect [208,209,211].

Pollyea et al. reported that the use of ventoclax with AZA disrupts energy metabolism in LSC, resulting in more durable remissions by inhibiting amino acid metabolism, leading to cell death. The effects of combinational therapy yielded much better results in comparison with conventional treatments [213]. Two years later, the second part of this study demonstrated resistance forming from a combinational therapy of venetoclax/AZA, which failed to eradicate LSCs in R/R patients caused by elevated nicotinamide metabolism. Metabolomic analysis reveals elevated nicotinamide causes in the activation of both amino acid metabolism and fatty acid oxidation resulting in oxidative phosphorylation. This provides means for LSCs to evade the cytotoxic effects of venetoclax/AZA therapy [214].

\subsubsection{IDH1/2 Inhibitors}

Ivosidenib is a potent orally available IDH1 inhibitor. It suppresses mutant IDH1 and hampers the synthesis of oncometabolite 2-HG, resulting in aberrant DNA and histone hypermethylation, differentiation arrest of the myeloid lineage, and initiation of leukemogenesis [215-217]. A phase 1 dose escalation and expansion trial was conducted on IDH1-mutated R/R MDS patients [215,218,219]. An ORR of $91.7 \%$ was entailed and $60 \%$ of patients remained in CR at 12 months, revealing the favorable response of ivosidenib in R/R MDS patients [215,218,219]. Olatusidenib (FT-2102) is another potent IDH1 inhibitor that restores cellular differentiation in MDS patients $[210,220]$. Clinical responses were seen in $33 \%$ and $73 \%$ with olatusidenib monotherapy and combination therapy, respectively, in 
a phase $1 / 2$ trial [220]. Safety and tolerability were depicted [220,221]. More clinical trials are currently underway (ClinicalTrials.gov Identifier: NCT02719574).

Enasidenib specifically targets IDH2 and could be used in MDS patients harboring IDH2 mutations. The effectiveness of enasidenib was recognized in the AG221-C-001 trial, where it not only gained FDA approval in 2017, but also evoked further investigations in IDH2-mutated R/R MDS patients [222-224]. OS was extended by around 3 times from 5 months to 16.9 months [222]. A phase 2 clinical trial was performed to further evaluate the tolerability and efficacy of enasidenib as a monotherapy or as a combination therapy with AZA [225,226]. Hopeful results as manifested with 100\% HMA-naïve HR-MDS patients responding to concurrent AZA-enasidenib therapy. Fifty percent of patients who were previously HMA-resistant were responsive to enasidenib monotherapy. In addition, most adverse effects were manageable, implying enasidenib is a tolerable novel agent in HRMDS patients [225,226]. Further clinical results are anticipated (ClinicalTrials.gov Identifier: NCT03744390; NCT03383575; NCT03839771).

\subsubsection{FLT3 Inhibitors}

Midostaurin is a first-generation type 1 FLT3 inhibitor that targets both FLT3-ITD and FLT3-TKD mutations. Concomitant use of midostaurin and AZA only showed an ORR of $26 \%$ in a phase $1 / 2$ study in FLT3-positive HR-MDS and AML patients [227]. As FLT3 mutation is associated with leukemogenesis, it is suggested that blast reduction is the most significant observation. Clinical response remains limited and was neither profound nor sustained enough to achieve CR [228]. Gilteritinib, a second-generation type 1 FLT3 inhibitor, was also investigated in MDS-EB-2 patients although the results have yet to be published (ClinicalTrials.gov Identifier: NCT04027309). Its use with venetoclax and AZA is also warranted (ClinicalTrials.gov Identifier: NCT04140487).

In contrast to midostaurin and gilteritinib, sorafenib is a first-generation type 2 FLT3 inhibitor with explicit FLT3-ITD inhibition. To date, the clinical efficacy of sorafenib has been limited and the results have been disappointing [118,229,230]. Co-treatment of sorafenib and a low dose cytarabine only demonstrated $10 \%$ ORR. The discouraging results might be explained by the use of low-dose cytarabine instead of HMAs, which is efficacious in MDS patients [118,230]. In addition, the off-targeting effect of sorafenib on vascular endothelial growth factor receptor (VEGFR) and platelet-derived growth factor receptor (PDGFR) give rise to unwanted adverse effects, such as hand-foot skin reaction [118]. Quizartinib is a second-generation type 2 FLT3 inhibitor. Multiple clinical trials with HMAs and/or FLT3 inhibitors are underway (ClinicalTrials.gov Identifier: NCT01892371; NCT03661307; NCT04493138). An interim report of the phase 1/2 trial showed that quizartinib exhibits an ORR of $67 \%$ in FLT3-ITD-mutated patients, which is higher than that of monotherapy [231]. Hence, this provides hope for FLT3-mutated MDS patients, especially those who are not candidates for allo-HSCT.

\subsection{Splicing Inhibition and TP53 Modulation}

The SF3b subcomplex is a component commonly targeted by splicing inhibitors [232,233]. They prevent the binding of SF3b subcomplex to pre-mRNA, leading to the blockade of spliceosome assembly [232,233]. Among the numerous splicing inhibitors, E1707 and H3B-8800 are the only two spliceosome inhibitors being tested in clinical settings [234]. E1707 is a pladienolide derivative targeting SF3B1 and was first evaluated in a phase 1 trial for advanced solid tumors $[235,236]$. However, further clinical investigation is discouraged as a patient developed optic neuritis. Nevertheless, its association with splicing inhibitors has not yet been corroborated [235]. H3B-8800 is a recently developed orally available splicing modulator that also binds to SF3b complexes, altering mRNA splicing and hence lethality [232-234,237]. A phase 1 clinical trial has been conducted, showing safety and a predictable pharmacokinetic profile in MDS, CMML, and AML patients [238]. Decreased transfusion independence has been also observed in $14 \%$ of patients [238]. Due to the investigation into the use of splicing inhibitors being early, the exciting results prompt 
further exploration. Inhibition of spliceosome mutations might be a potential therapeutic option in MDS patients in the future.

Eprenetapopt (APR-246) is a novel small molecule that spares normal cells, while it covalently binds to mutant and wild-type p53 to thermodynamically stabilize p53 mutants for reactivation of its functions and restoring the conformation of misfolded p53 wildtype proteins to ultimately eradicate leukemic cells [239-242]. In a phase Ib/II study, combination of eprenetapopt with azacitidine resulted in an ORR of 73\% in MDS with 50\% achieving CR and 58\% achieving a cytogenetic response [243].

\subsection{Immune Checkpoint Inhibition in Combination with HMA \\ 4.6.1. Anti-PD-1, Anti-PD-L1, Anti-CTLA-4}

The elevated levels of PD-1 and PD-L1 have been found in patients after treatment of HMAs or in the case of HMA failure, albeit discovering no significant association between level of PD-1 expression with response to HMA [146]. This sheds light on immune checkpoint molecules as therapeutic targets for the development of immune checkpoint inhibitors and as potential agents in refractory disease. Pembrolizumab (MK-3475) and nivolumab are both humanized monoclonal antibodies (mAbs) that serve as anti-PD-1 inhibitors. Durvalumab (MEDI4736) and atezolizumab, on the other hand, act as anti-PD-L1 inhibitors. Ipilimumab is an anti-CTLA-4 inhibitor (Table 1).

Table 1. List of clinical trials on novel agents and combinatorial treatment for MDS.

\begin{tabular}{|c|c|c|c|c|c|c|}
\hline \multicolumn{2}{|c|}{ Drug } & Phase & Disease Subtype & Regimen & Status & $\begin{array}{l}\text { Clinical Trial } \\
\text { Identifier }\end{array}$ \\
\hline \multicolumn{7}{|c|}{ Immune Checkpoint Inhibitors } \\
\hline \multirow{4}{*}{ Pembrolizumab } & \multirow{6}{*}{ Anti-PD1 } & 1 & $\begin{array}{l}\text { Hematologic } \\
\text { malignancies }\end{array}$ & Pembrolizumab & Completed & NCT01953692 \\
\hline & & 1 & MDS & $\begin{array}{c}\text { Pembrolizumab + } \\
\text { Entinostat }\end{array}$ & $\begin{array}{l}\text { Active, not } \\
\text { recruiting }\end{array}$ & NCT02936752 \\
\hline & & 2 & MDS & Pembrolizumab + AZA & Recruiting & NCT03094637 \\
\hline & & 1 & ND/RR AML/MDS & Pembrolizumab + DEC & Recruiting & NCT03969446 \\
\hline \multirow[b]{2}{*}{ Nivolumab } & & 2 & MDS, R/R MDS & $\begin{array}{l}\text { Nivolumab + AZA, } \\
\text { Ipilimumab + AZA }\end{array}$ & Recruiting & NCT02530463 \\
\hline & & $2 / 3$ & AML, MDS & $\begin{array}{c}\text { AZA + } \\
\text { Nivolumab/Midostaurin, } \\
\text { DEC + Cytarabine }\end{array}$ & $\begin{array}{l}\text { Active, not } \\
\text { recruiting }\end{array}$ & NCT03092674 \\
\hline \multirow{3}{*}{$\begin{array}{c}\text { Durvalumab } \\
\text { (MEDI4736) }\end{array}$} & \multirow{3}{*}{ Anti-PD-L1 } & 1 & MDS & $\begin{array}{c}\text { Durvalumab, } \\
\text { Durvalumab }+ \\
\text { Tremelimumab }\end{array}$ & Completed & NCT02117219 \\
\hline & & 2 & MDS & Durvalumab + AZA & $\begin{array}{l}\text { Active, not } \\
\text { recruiting }\end{array}$ & NCT02281084 \\
\hline & & 2 & AML, MDS & $\begin{array}{l}\text { AZA, AZA + } \\
\text { Durvalumab }\end{array}$ & $\begin{array}{l}\text { Active, not } \\
\text { recruiting }\end{array}$ & NCT02775903 \\
\hline Ipilimumab & Anti-CTLA-4 & 1 & R/R MDS, AML & Ipilimumab + DEC & Recruiting & NCT02890329 \\
\hline \multirow{5}{*}{$\begin{array}{l}\text { Sabatolimab } \\
\text { (MBG453) }\end{array}$} & \multirow{5}{*}{ Anti-TIM-3 } & 1 & AML, HR-MDS & $\begin{array}{c}\text { MBG453, or in } \\
\text { combination with } \\
\text { PDR001/DEC/AZA }\end{array}$ & $\begin{array}{l}\text { Active, not } \\
\text { recruiting }\end{array}$ & NCT03066648 \\
\hline & & 2 & HR-MDS & MBG453 + HMA & $\begin{array}{l}\text { Active, not } \\
\text { recruiting }\end{array}$ & NCT03946670 \\
\hline & & 3 & HR-MDS, CMML-2 & MBG453 + AZA & Recruiting & NCT04266301 \\
\hline & & 2 & HR-MDS & $\begin{array}{c}\text { Sabatolimab + AZA + } \\
\text { Venetoclax }\end{array}$ & Not yet recruiting & NCT04812548 \\
\hline & & 2 & HR-MDS & $\begin{array}{l}\text { Sabatolimab + } \\
\text { AZA/DEC }\end{array}$ & Not yet recruiting & NCT04878432 \\
\hline TTI-621 (SIRP $\left.\alpha \mathrm{Fc}_{\mathrm{c}}\right)$ & \multirow{4}{*}{ Anti-CD47 } & 1 & $\begin{array}{l}\text { Hematologic } \\
\text { malignancies, solid } \\
\text { tumors }\end{array}$ & TTI-621 for MDS & Recruiting & NCT02663518 \\
\hline \multirow[t]{2}{*}{ Magrolimab } & & 1 & $\begin{array}{l}\text { Hematologic } \\
\text { malignancies }\end{array}$ & $\begin{array}{c}\text { Magrolimab, } \\
\text { Magrolimab + AZA }\end{array}$ & Recruiting & NCT03248479 \\
\hline & & 3 & MDS & $\begin{array}{l}\text { AZA, AZA + } \\
\text { Magrolimab }\end{array}$ & Recruiting & NCT04313881 \\
\hline AK117 & & $1 / 2$ & MDS & AK117 + AZA & Recruiting & NCT04900350 \\
\hline
\end{tabular}


Monotherapy with pembrolizumab or ipilimumab exhibited suboptimal responses in HMA-resistant patients with ORRs of $4 \%$ and $3.4 \%$, respectively (NCT01953692) [244,245]. Nevertheless, a phase 2 trial done by Chien et al. showed the potential anti-leukemic effect of pembrolizumab with AZA in HMA-resistant patients (NCT03094637) [246]. Another phase 2 trial conducted by Garcia-Manero et al. also preliminarily observed superior therapeutic effects for nivolumab or ipilimumab as a combination therapy with AZA, with ORRs of $75 \%$ and $71 \%$, and median survivals of 12 months and not reached, respectively. A better synergistic response was observed in ipilimumab than with nivolumab with AZA [247]. However, they both performed poorly as single agents (both with median survivals of 8 months), which was supported by another phase 2 study showing ORRs of $0 \%$ and $22 \%$ in nivolumab and ipilimumab, respectively $[247,248]$. The use of nivolumab with AZA also displays anti-leukemic effect in de novo MDS patients with an ORR of 69\% [248]. Notably, the addition of the anti-PD-L1, durvalumab, to AZA also augmented the ORR in HR-MDS, as demonstrated in a study performed by Zeidan et al. (ORRs: $61.9 \%$ vs. $47.6 \%$ ) (NCT02775903) [249]. Atezolizumab, on the other hand, has demonstrated limited efficacy with unfavorable safety when engaged with AZA [250]. Clinical trials on the combination of pembrolizumab with entinostat, a HDAC inhibitor, or DEC are underway (NCT02936752, NCT03969446). Other trials combining nivolumab, ipilimuma or durvalumab with HMA are also being evaluated (NCT02117219, NCT02281084, NCT02530463, NCT02890329, NCT03092674).

\subsubsection{Anti-TIM-3}

The introduction of anti-TIM-3 antibodies put an end to the proliferation of leukemic blasts. This finding eventually led to the development of $\mathrm{mAb}$ antagonizing TIM-3 receptors as a possible novel treatment for HR-MDS [251]. A phase $1 \mathrm{~b}$ study carried out by Borate et al. demonstrated that the use of DEC with sabatolimab in HR-MDS can achieve $50 \% \mathrm{CR}$ and molecular CR (mCR) [252]. In addition, another phase $1 \mathrm{~b}$ trial conducted by Brunner et al. showed an ORR of $62.9 \%$ with superior response in very high risk IPSS-R than high risk IPSS-R patients ( $84.6 \%$ vs. 50\%) [251]. A phase 1 trial is currently in progress, studying the safety and tolerability of sabatolimab alone and in combination with AZA or DEC (NCT03066648). Phase 2, STIMULUS-MDS1 (NCT03946670), and phase 3, STIMULUSMDS2 (NCT04266301), trials are also underway, evaluating the efficacy of the combination of sabatolimab with HMAs [153]. This prompts further development of several impending phases 2 trials, STIMULUS-MDS3 and STIMULUS MDS-US, evaluating the efficacy of sabatolimab in conjunction with HMAs in HR-MDS (NCT04812548, NCT04878432).

\subsubsection{Anti-CD47}

With CD47 overexpressed in MDS and the binding of CD47 to SIRP $\alpha$ prevents MDS cells from phagocytosis, the blockade of such interactions promotes antibody-dependent cytotoxic phagocytosis of the tumor cells opsonized with antibodies [253]. This has led to the introduction of magrolimab, TTI-621, and CC-90002 as anti-47 mAbs for therapeutic advancement in MDS [168-170]. Magrolimab (Hu5F9-G4) is a mAb targeting malignant cells via macrophage phagocytosis. It serves as a checkpoint inhibitor of macrophages that exhibits anti-phagocytic properties [253]. Despite the limited efficacy of magrolimab as a monotherapy, its use as a combinatory drug exhibits potential synergistic effects. Sallman et al. conducted a phase $1 \mathrm{~b}$ trial on the use of magrolimab with AZA and evaluated its efficacy in MDS and AML patients. Objective response was seen in all de novo MDS patients in the study. The combination significantly shortened the time to response by a median of 1.9 months when compared with AZA alone [254]. This led to the expansion of the trial, which has demonstrated a pronounced objective response of 91\% in HR-MDS patients, suggesting that magroliumab is a promising therapeutic candidate for the development of future novel drugs (NCT03248479) [255]. TTI-621, also known as signal regulatory protein $\alpha-\mathrm{Fc}(\mathrm{SIRP} \alpha \mathrm{Fc})$, also entered a phase 1 trial, evaluating its effectiveness as a single agent in MDS (NCT02663518). Currently, a phase 3 trial, ENHANCE, is underway, comparing the 
efficacy of the synergy between magrolimab and AZA and AZA alone (NCT04313881) [196]. Other ongoing trials are also under investigation (NCT03248479). AK117, a novel IgG4 mAb antagonizing CD47, was also tested in a phase $1 / 2$ trial for safety and efficacy assessment in HR-MDS (NCT04900350).

\subsection{Adoptive T-Cell Therapy with HMA or as Monotherapy}

Adoptive T-cell therapy is the infusion of T-lymphocytes into a patient's body to directly target an antigen, resulting in an increase of cytotoxicity for the target cell. Tcell transfers can be autologous or allogeneic, which can be an unmanipulated transfer (donor lymphocyte infusion) or a manipulated transfer, such as ex-vivo priming with onco-antigens, chimeric antigen receptor (CAR) T-cell constructs and modified T-cell receptors. For example, by immunizing with antigens, there are in vitro studies conducted to find ways to manipulate lymphocytes and target myeloid antigens for patients with MDS. There are only two phase 1 clinical trials of CAR T-cell therapy on intermediate to HR-MDS patients or patients failing HMA (ClinicalTrials.gov Identifier: NCT-03258359; NCT02203825); results have not yet been published.

\subsubsection{Anti-CD123}

Steven et al. demonstrated that cell surface antigen CD123 is overexpressed on MDS stem cells [256], with a gradual increase of CD123 expression from LR-MDS, intermediate to HR-MDS [257]. CD123 CAR-T cells eradicated CD123 ${ }^{+}$MDS stem cells in vitro as a proofof-concept for a valid treatment for high risk MDS patients. While eradicating CD123 ${ }^{+}$ MDS stem cells may substantially reduce disease burden residuals of CD123 negative/low the MDS stem cells that were left behind are still of concern. Li et al. demonstrated that $\mathrm{CD} 34^{+} \mathrm{CD} 123^{+}$stem population is not as abundant in LR-MDS and intermediate risk MDS in comparison with HR-MDS patients, postulating that MDS stem cells in these patients will not be effectively targeted by CD123 CAR T-cells [257].

\subsubsection{Anti-NKG2D}

The natural killer group 2 receptors (NKG2D) are positive immunomodulatory proteins found on NK and $\mathrm{CD} 8^{+} \mathrm{T}$ cells. When there is a presence of intracellular stress, such as DNA damage, infections, inflammation, and toxins, cancer cells express high levels of the MHC I chain-related protein A/B (MICA/B), which are ligands for NK2GD hence inducing tumor elimination by NK-mediated or CD8 ${ }^{+}$T-cell $[258,259]$. In $~ 30 \%$ of MDS patients, protein expression of both MICA and MICB is found in $\mathrm{CD} 34^{+}$cells. At the same time, NKG2D is downregulated in MDS patients and is correlated with impaired NK-mediated cytotoxicity. Moreover, impaired NK function in MDS has been reported with significant associations to higher IPSS risk, abnormal karyotype, excess blasts percentage, and marrow hypercellularity [260]. Other pre-clinical models have also been reported on the extended potential of NKG2D CAR T-cells, such as in the overexpression of the receptor to overcome natural inhibition mediated by MICA [261-263] and the co-stimulation of CD28 for T cell activation and survival through the activation of DNAX-activating protein of $10 \mathrm{kDa}$ (DAP10) $[264,265]$. These data collectively confirm the evasion of NK surveillance by MDS cells, prompting the development of CAR T-cell therapy targeting this axis [266].

Genetically engineered T-cells to express NKG2D have demonstrated the potential to specifically target, not just cancer cells, but also Tregs and myeloid-derived suppressor cells within the tumor microenvironment [267]. Clinical trials of NKG2D CAR T-cells in MDS patients showed the overexpression of the ligands for NKG2D $[267,268]$. Ongoing phase I trials (ClinicalTrials.gov Identifier: NCT02203825) are now underway but preliminary reports have demonstrated NKG2D CAR T-cells with transient hematologic improvement against autologous tumor cells in vitro of MDS patients [265]. 


\subsection{Donor-Derived Lymphocytes against Tumor-Associated Antigens}

Relapse following allogeneic HSCT is associated with a dismal outcome [269]. Unmanipulated donor cell infusion (DLI) or second allogeneic HSCT may be considered but responses are often unpredictable [270,271]. Patient-specific DLI with tumor-associated antigen (TAA) stimulation ex vivo selects for an enriched, polyclonal $\mathrm{CD} 4^{+}$and $\mathrm{CD} 8^{+}$ specifically target myeloid malignancies have shown promises in aiding advanced treatment in MDS. Lulla et al. were able to mitigate GVHD with non-manipulated DLI by selecting T-cells with specific MDS antigens that are not typically present on normal host cells, such as NYESO1, PRAME, Survivin, and WT1. Twelve patients who received TAAcell prophylaxis $(n=12)$ had 4 relapses within 1 year of infusion, of which the 11 patients that received tailored DLI TAA-T cells remain alive. Respondents to the treatment had a measurable expansion of leukemia antigen specific T-cells which persisted for over 9 months with no experience of any infusion related GVHD [272].

TAA-DLI has shown potential in disease control compared with unselected donor T cell infusion in post-transplant settings; however, its limitations lie with the productivity of the T-cells as its highly dependent on donor availability. The utilization of autologous CAR $\mathrm{T}$ therapy in MDS remains uncertain. There are many problems that must be overcome such as the inability to persist with $\mathrm{T}$ cell response memories problematic for this to be a make a valid therapy option for HR-MDS. Through CAR T cell expansion processes, problems, such as the immunosuppressive and impair immune effects, can be rectified and reinforce the central dogma of the bone marrow microenvironment in MDS $[273,274]$. NK cell therapy has also been reported to be a well-tolerated therapy for HR-MDS or patients refractory to chemotherapy [158]. Although tested in only a very few MDS patients, Björklund et al. reported that infusion of haploid identical NK cells from a healthy donors can reduce the allelic burden of tumor cell clones with high risk ASXL1 and RUNX1 mutations. MDS patients responding to this treatment also shows undetectable mutations upon therapy.

\section{Conclusions}

MDS is a clonal hematological disease with substantial genetic and epigenetic complexity and heterogeneity. The genomic profile should be incorporated into the personalized prognostic assessment of MDS and therapeutic targeting with novel agents. To overcome HMA resistance, combinatorial approaches involving novel agents and HMA are required. These include molecular targeted therapy and immune checkpoint inhibition.

Author Contributions: Conceptualization, H.G.; writing-original draft preparation, P.L., R.Y., Y.Y., H.-T.C., P.-K.Y.; writing-review and editing, H.G.; supervision, H.G. All authors have read and agreed to the published version of the manuscript.

Funding: This research received no external funding.

Institutional Review Board Statement: Not applicable.

Informed Consent Statement: Not applicable.

Conflicts of Interest: The authors declare no conflict of interest.

\section{References}

1. Patnaik, M.M.; Tefferi, A. Myelodysplastic syndromes with ring sideroblasts (MDS-RS) and MDS/myeloproliferative neoplasm with RS and thrombocytosis (MDS/MPN-RS-T) — “2021 update on diagnosis, risk-stratification, and management”. Am. J. Hematol. 2021, 96, 379-394. [CrossRef] [PubMed]

2. Alessandrino, E.P.; Della Porta, M.G.; Bacigalupo, A.; Van Lint, M.T.; Falda, M.; Onida, F.; Bernardi, M.; Iori, A.P.; Rambaldi, A.; Cerretti, R.; et al. WHO classification and WPSS predict posttransplantation outcome in patients with myelodysplastic syndrome: A study from the Gruppo Italiano Trapianto di Midollo Osseo (GITMO). Blood 2008, 112, 895-902. [CrossRef] [PubMed]

3. Stevens, B.M.; Khan, N.; D’Alessandro, A.; Nemkov, T.; Winters, A.; Jones, C.L.; Zhang, W.; Pollyea, D.A.; Jordan, C.T. Characterization and targeting of malignant stem cells in patients with advanced myelodysplastic syndromes. Nat. Commun. 2018, 9, 3694. [CrossRef] [PubMed]

4. Wang, C.; Yang, Y.; Gao, S.; Chen, J.; Yu, J.; Zhang, H.; Li, M.; Zhan, X.; Li, W. Immune dysregulation in myelodysplastic syndrome: Clinical features, pathogenesis and therapeutic strategies. Crit. Rev. Oncol. Hematol. 2018, 122, 123-132. [CrossRef] [PubMed] 
5. Cazzola, M.; Malcovati, L.; Invernizzi, R. Myelodysplastic/myeloproliferative neoplasms. Hematol. Am. Soc. Hematol. Educ. Program. 2011, 2011, 264-272. [CrossRef] [PubMed]

6. Corrêa de Souza, D.; de Souza Fernandez, C.; Camargo, A.; Apa, A.G.; Sobral da Costa, E.; Bouzas, L.F.; Abdelhay, E.; de Souza Fernandez, T. Cytogenetic as an Important Tool for Diagnosis and Prognosis for Patients with Hypocellular Primary Myelodysplastic Syndrome. BioMed. Res. Int. 2014, 2014, 542395. [CrossRef]

7. Bejar, R. Clinical and genetic predictors of prognosis in myelodysplastic syndromes. Haematologica 2014, 99, 956-964. [CrossRef] [PubMed]

8. Xu, Y.; Li, Y.; Xu, Q.; Chen, Y.; Lv, N.; Jing, Y.; Dou, L.; Bo, J.; Hou, G.; Guo, J.; et al. Implications of mutational spectrum in myelodysplastic syndromes based on targeted next-generation sequencing. Oncotarget 2017, 8, 82475-82490. [CrossRef]

9. Bejar, R.; Stevenson, K.; Abdel-Wahab, O.; Galili, N.; Nilsson, B.; Garcia-Manero, G.; Kantarjian, H.; Raza, A.; Levine, R.L.; Neuberg, D.; et al. Clinical effect of point mutations in myelodysplastic syndromes. N. Engl. J. Med. 2011, 364, 2496-2506. [CrossRef]

10. Langemeijer, S.M.; Kuiper, R.P.; Berends, M.; Knops, R.; Aslanyan, M.G.; Massop, M.; Stevens-Linders, E.; van Hoogen, P.; van Kessel, A.G.; Raymakers, R.A.; et al. Acquired mutations in TET2 are common in myelodysplastic syndromes. Nat. Genet. 2009, 41, 838-842. [CrossRef]

11. Yoshida, K.; Sanada, M.; Shiraishi, Y.; Nowak, D.; Nagata, Y.; Yamamoto, R.; Sato, Y.; Sato-Otsubo, A.; Kon, A.; Nagasaki, M.; et al. Frequent pathway mutations of splicing machinery in myelodysplasia. Nature 2011, 478, 64-69. [CrossRef] [PubMed]

12. Raza, A.; Galili, N. The genetic basis of phenotypic heterogeneity in myelodysplastic syndromes. Nat. Rev. Cancer 2012, 12, 849-859. [CrossRef] [PubMed]

13. Haferlach, T.; Nagata, Y.; Grossmann, V.; Okuno, Y.; Bacher, U.; Nagae, G.; Schnittger, S.; Sanada, M.; Kon, A.; Alpermann, T.; et al. Landscape of genetic lesions in 944 patients with myelodysplastic syndromes. Leukemia 2014, 28, 241-247. [CrossRef] [PubMed]

14. Nazha, A.; Narkhede, M.; Radivoyevitch, T.; Seastone, D.J.; Patel, B.J.; Gerds, A.T.; Mukherjee, S.; Kalaycio, M.; Advani, A.; Przychodzen, B.; et al. Incorporation of molecular data into the Revised International Prognostic Scoring System in treated patients with myelodysplastic syndromes. Leukemia 2016, 30, 2214-2220. [CrossRef]

15. Gu, S.; Xia, J.; Tian, Y.; Zi, J.; Ge, Z. A novel scoring system integrating molecular abnormalities with IPSS-R can improve the risk stratification in patients with MDS. BMC Cancer 2021, 21, 134. [CrossRef]

16. Bersanelli, M.; Travaglino, E.; Meggendorfer, M.; Matteuzzi, T.; Sala, C.; Mosca, E.; Chiereghin, C.; Di Nanni, N.; Gnocchi, M.; Zampini, M.; et al. Classification and Personalized Prognostic Assessment on the Basis of Clinical and Genomic Features in Myelodysplastic Syndromes. J. Clin. Oncol. 2021, 39, 1223-1233. [CrossRef]

17. Gangat, N.; Mudireddy, M.; Lasho, T.L.; Finke, C.M.; Nicolosi, M.; Szuber, N.; Patnaik, M.M.; Pardanani, A.; Hanson, C.A.; Ketterling, R.P.; et al. Mutations and prognosis in myelodysplastic syndromes: Karyotype-adjusted analysis of targeted sequencing in 300 consecutive cases and development of a genetic risk model. Am. J. Hematol. 2018, 93, 691-697. [CrossRef] [PubMed]

18. Tefferi, A.; Lasho, T.L.; Patnaik, M.M.; Saeed, L.; Mudireddy, M.; Idossa, D.; Finke, C.; Ketterling, R.P.; Pardanani, A.; Gangat, N. Targeted next-generation sequencing in myelodysplastic syndromes and prognostic interaction between mutations and IPSS-R. Am. J. Hematol. 2017, 92, 1311-1317. [CrossRef]

19. Gao, J.; Swaminathan, S.; Pai, N.; Johnson, Z.; Chen, Y.H.; Peterson, L.; Goolsby, C. Flow cytometric detection of altered signaling in myelodysplastic syndrome and cytopenia. Leuk. Res. 2015, 39, 1396-1404. [CrossRef] [PubMed]

20. Frohling, S.; Schlenk, R.F.; Breitruck, J.; Benner, A.; Kreitmeier, S.; Tobis, K.; Dohner, H.; Dohner, K. Prognostic significance of activating FLT3 mutations in younger adults (16 to 60 years) with acute myeloid leukemia and normal cytogenetics: A study of the AML Study Group Ulm. Blood 2002, 100, 4372-4380. [CrossRef] [PubMed]

21. Gill, H.; Leung, A.Y.; Kwong, Y.L. Molecular and Cellular Mechanisms of Myelodysplastic Syndrome: Implications on Targeted Therapy. Int. J. Mol. Sci. 2016, 17, 440. [CrossRef] [PubMed]

22. Rocnik, J.L.; Okabe, R.; Yu, J.C.; Lee, B.H.; Giese, N.; Schenkein, D.P.; Gilliland, D.G. Roles of tyrosine 589 and 591 in STAT5 activation and transformation mediated by FLT3-ITD. Blood 2006, 108, 1339-1345. [CrossRef]

23. Georgiou, G.; Karali, V.; Zouvelou, C.; Kyriakou, E.; Dimou, M.; Chrisochoou, S.; Greka, P.; Dufexis, D.; Vervesou, E.; Dimitriadou, E.; et al. Serial determination of FLT3 mutations in myelodysplastic syndrome patients at diagnosis, follow up or acute myeloid leukaemia transformation: Incidence and their prognostic significance. Br. J. Haematol. 2006, 134, 302-306. [CrossRef]

24. Daver, N.; Strati, P.; Jabbour, E.; Kadia, T.; Luthra, R.; Wang, S.; Patel, K.; Ravandi, F.; Cortes, J.; Qin Dong, X.; et al. FLT3 mutations in myelodysplastic syndrome and chronic myelomonocytic leukemia. Am. J. Hematol. 2013, 88, 56-59. [CrossRef] [PubMed]

25. Kim, T.; Tyndel, M.S.; Kim, H.J.; Ahn, J.S.; Choi, S.H.; Park, H.J.; Kim, Y.K.; Yang, D.H.; Lee, J.J.; Jung, S.H.; et al. The clonal origins of leukemic progression of myelodysplasia. Leukemia 2017, 31, 1928-1935. [CrossRef] [PubMed]

26. Zhan, D.; Park, C.Y. Stem Cells in the Myelodysplastic Syndromes. Front. Aging 2021, 2. [CrossRef]

27. Rouault-Pierre, K.; Smith, A.E.; Mian, S.A.; Pizzitola, I.; Kulasekararaj, A.G.; Mufti, G.J.; Bonnet, D. Myelodysplastic syndrome can propagate from the multipotent progenitor compartment. Haematologica 2017, 102, e7-e10. [CrossRef]

28. Orfao, A.; Garcia-Montero, A.C.; Sanchez, L.; Escribano, L. Recent advances in the understanding of mastocytosis: The role of KIT mutations. Br. J. Haematol. 2007, 138, 12-30. [CrossRef]

29. Lorenzo, F.; Nishii, K.; Monma, F.; Kuwagata, S.; Usui, E.; Shiku, H. Mutational analysis of the KIT gene in myelodysplastic syndrome (MDS) and MDS-derived leukemia. Leuk. Res. 2006, 30, 1235-1239. [CrossRef] 
30. Craig, J.W.; Hasserjian, R.P.; Kim, A.S.; Aster, J.C.; Pinkus, G.S.; Hornick, J.L.; Steensma, D.P.; Coleman Lindsley, R.; DeAngelo, D.J.; Morgan, E.A. Detection of the KIT(D816V) mutation in myelodysplastic and/or myeloproliferative neoplasms and acute myeloid leukemia with myelodysplasia-related changes predicts concurrent systemic mastocytosis. Mod. Pathol. 2020, 33, 1135-1145. [CrossRef]

31. Shao, Z.; Zhang, H.; Chen, G.; Wang, L.; Li, K.; Zhang, Y.; Li, L.; Sun, J. Expression and function of c-kit receptor in bone marrow mononuclear cells of patients with myelodysplastic syndromes. Chin. Med. J. 2001, 114, 481-485.

32. Russkamp, N.F.; Myburgh, R.; Kiefer, J.D.; Neri, D.; Manz, M.G. Anti-CD117 immunotherapy to eliminate hematopoietic and leukemia stem cells. Exp. Hematol. 2021, 95, 31-45. [CrossRef] [PubMed]

33. Ganguly, B.B.; Kadam, N.N. Mutations of myelodysplastic syndromes (MDS): An update. Mutat Res. Rev. Mutat Res. 2016, 769, 47-62. [CrossRef] [PubMed]

34. Al-Kali, A.; Luthra, R.; Bueso-Ramos, C.E.; Pierce, S.; Kadia, T.; Borthakur, G.; Estrov, Z.; Jabbour, E.; Faderl, S.; Ravandi, F.; et al. Impact of RAS Mutations In Myelodysplastic Syndrome (MDS). Blood 2010, 116, 2926. [CrossRef]

35. Paquette, R.L.; Landaw, E.M.; Pierre, R.V.; Kahan, J.; Lubbert, M.; Lazcano, O.; Isaac, G.; McCormick, F.; Koeffler, H.P. Nras mutations are associated with poor prognosis and increased risk of leukemia in myelodysplastic syndrome. Blood 1993, 82, 590-599. [CrossRef]

36. Hirai, H.; Okada, M.; Mizoguchi, H.; Mano, H.; Kobayashi, Y.; Nishida, J.; Takaku, F. Relationship between an activated N-ras oncogene and chromosomal abnormality during leukemic progression from myelodysplastic syndrome. Blood 1988, 71, 256-258. [CrossRef] [PubMed]

37. Sanada, M.; Suzuki, T.; Shih, L.Y.; Otsu, M.; Kato, M.; Yamazaki, S.; Tamura, A.; Honda, H.; Sakata-Yanagimoto, M.; Kumano, K.; et al. Gain-of-function of mutated C-CBL tumour suppressor in myeloid neoplasms. Nature 2009, 460, 904-908. [CrossRef] [PubMed]

38. Katzav, S.; Schmitz, M.L. Mutations of c-Cbl in myeloid malignancies. Oncotarget 2015, 6, 10689-10696. [CrossRef]

39. Reindl, C.; Quentmeier, H.; Petropoulos, K.; Greif, P.A.; Benthaus, T.; Argiropoulos, B.; Mellert, G.; Vempati, S.; Duyster, J.; Buske, C.; et al. CBL exon 8/9 mutants activate the FLT3 pathway and cluster in core binding factor/11q deletion acute myeloid leukemia/myelodysplastic syndrome subtypes. Clin. Cancer Res. 2009, 15, 2238-2247. [CrossRef]

40. Schwaab, J.; Ernst, T.; Erben, P.; Rinke, J.; Schnittger, S.; Strobel, P.; Metzgeroth, G.; Mossner, M.; Haferlach, T.; Cross, N.C.; et al. Activating CBL mutations are associated with a distinct MDS/MPN phenotype. Ann. Hematol. 2012, 91, 1713-1720. [CrossRef]

41. Minakuchi, M.; Kakazu, N.; Gorrin-Rivas, M.J.; Abe, T.; Copeland, T.D.; Ueda, K.; Adachi, Y. Identification and characterization of SEB, a novel protein that binds to the acute undifferentiated leukemia-associated protein SET. Eur. J. Biochem. 2001, 268, 1340-1351. [CrossRef] [PubMed]

42. Li, M.; Makkinje, A.; Damuni, Z. The myeloid leukemia-associated protein SET is a potent inhibitor of protein phosphatase 2A. J. Biol. Chem. 1996, 271, 11059-11062. [CrossRef]

43. Oakley, K.; Han, Y.; Vishwakarma, B.A.; Chu, S.; Bhatia, R.; Gudmundsson, K.O.; Keller, J.; Chen, X.; Vasko, V.; Jenkins, N.A.; et al. Setbp1 promotes the self-renewal of murine myeloid progenitors via activation of Hoxa9 and Hoxa10. Blood 2012, 119, 6099-6108. [CrossRef]

44. Makishima, H.; Yoshida, K.; Nguyen, N.; Przychodzen, B.; Sanada, M.; Okuno, Y.; Ng, K.P.; Gudmundsson, K.O.; Vishwakarma, B.A.; Jerez, A.; et al. Somatic SETBP1 mutations in myeloid malignancies. Nat. Genet. 2013, 45, 942-946. [CrossRef] [PubMed]

45. Shou, L.H.; Cao, D.; Dong, X.H.; Fang, Q.; Wu, Y.; Zhang, Y.; Fei, J.P.; Xu, B.L. Prognostic significance of SETBP1 mutations in myelodysplastic syndromes, chronic myelomonocytic leukemia, and chronic neutrophilic leukemia: A meta-analysis. PLoS ONE 2017, 12, e0171608. [CrossRef] [PubMed]

46. Coccaro, N.; Tota, G.; Zagaria, A.; Anelli, L.; Specchia, G.; Albano, F. SETBP1 dysregulation in congenital disorders and myeloid neoplasms. Oncotarget 2017, 8, 51920. [CrossRef]

47. Hou, H.-A.; Kuo, Y.-Y.; Tang, J.-L.; Chou, W.-C.; Yao, M.; Lai, Y.-J.; Lin, C.-C.; Chen, C.-Y.; Liu, C.-Y.; Tseng, M.-H.; et al. Clinical implications of the SETBP1 mutation in patients with primary myelodysplastic syndrome and its stability during disease progression. Am. J. Hematol. 2014, 89, 181-186. [CrossRef]

48. Adema, V.; Larrayoz, M.J.; Calasanz, M.J.; Palomo, L.; Patino-Garcia, A.; Agirre, X.; Hernandez-Rivas, J.M.; Lumbreras, E.; Buno, I.; Martinez-Laperche, C.; et al. Correlation of myelodysplastic syndromes with i(17)(q10) and TP53 and SETBP1 mutations. Br. J. Haematol. 2015, 171, 137-141. [CrossRef]

49. Thol, F.; Suchanek, K.J.; Koenecke, C.; Stadler, M.; Platzbecker, U.; Thiede, C.; Schroeder, T.; Kobbe, G.; Kade, S.; Loffeld, P.; et al. SETBP1 mutation analysis in 944 patients with MDS and AML. Leukemia 2013, 27, 2072-2075. [CrossRef]

50. Piazza, R.; Valletta, S.; Winkelmann, N.; Redaelli, S.; Spinelli, R.; Pirola, A.; Antolini, L.; Mologni, L.; Donadoni, C.; Papaemmanuil, E.; et al. Recurrent SETBP1 mutations in atypical chronic myeloid leukemia. Nat. Genet. 2013, 45, 18-24. [CrossRef]

51. Saika, M.; Inoue, D.; Nagase, R.; Sato, N.; Tsuchiya, A.; Yabushita, T.; Kitamura, T.; Goyama, S. ASXL1 and SETBP1 mutations promote leukaemogenesis by repressing TGFbeta pathway genes through histone deacetylation. Sci. Rep. 2018, 8, 15873. [CrossRef] [PubMed]

52. Varnum-Finney, B.; Xu, L.; Brashem-Stein, C.; Nourigat, C.; Flowers, D.; Bakkour, S.; Pear, W.S.; Bernstein, I.D. Pluripotent, cytokine-dependent, hematopoietic stem cells are immortalized by constitutive Notch1 signaling. Nat. Med. 2000, 6, $1278-1281$. [CrossRef] [PubMed] 
53. Weickert, M.-T.; Hecker, J.S.; Buck, M.C.; Schreck, C.; Rivière, J.; Schiemann, M.; Schallmoser, K.; Bassermann, F.; Strunk, D.; Oostendorp, R.A.J.; et al. Bone marrow stromal cells from MDS and AML patients show increased adipogenic potential with reduced Delta-like-1 expression. Sci. Rep. 2021, 11, 5944. [CrossRef] [PubMed]

54. Kang, Y.A.; Pietras, E.M.; Passegue, E. Deregulated Notch and Wnt signaling activates early-stage myeloid regeneration pathways in leukemia. J. Exp. Med. 2020, 217. [CrossRef] [PubMed]

55. Aref, S.; Rizk, R.; El Agder, M.; Fakhry, W.; El Zafarany, M.; Sabry, M. NOTCH-1 Gene Mutations Influence Survival in Acute Myeloid Leukemia Patients. Asian Pac. J. Cancer Prev. 2020, 21, 1987-1992. [CrossRef] [PubMed]

56. Montalban-Bravo, G.; Pierola, A.A.; Takahashi, K.; Konopleva, M.; Jabbour, E.; Borthakur, G.; Daver, N.G.; Dinardo, C.D.; Estrov, Z.; Kadia, T.M.; et al. Clinical relevance of mutations in patients with myelodysplastic syndromes and myelodysplastic/myeloproliferative neoplasms with normal karyotype. J. Clin. Oncol. 2017, 35, 7053. [CrossRef]

57. Fu, L.; Nara, N.; Tohda, S. Involvement of Notch signaling in myelodysplastic syndrome. Leuk. Res. 2007, 31, 1160-1161. [CrossRef]

58. Beekman, R.; Touw, I.P. G-CSF and its receptor in myeloid malignancy. Blood 2010, 115, 5131-5136. [CrossRef]

59. Gunawan, A.S.; McLornan, D.P.; Wilkins, B.; Waghorn, K.; Hoade, Y.; Cross, N.C.P.; Harrison, C.N. Ruxolitinib, a potent JAK1/JAK2 inhibitor, induces temporary reductions in the allelic burden of concurrent CSF3R mutations in chronic neutrophilic leukemia. Haematologica 2017, 102, e238-e240. [CrossRef]

60. Liu, H.; Zhang, Y.; Wang, F.; Chen, X.; Teng, W.; Wang, M.; Zhang, Y.; Liu, H. CSF3R Mutation in Acute Leukemia and MDS Patients. Blood 2017, 130, 2669. [CrossRef]

61. Fermo, E.; Zaninoni, A.; Imperiali, F.G.; Bianchi, P.; Colombi, M.; Barcellini, W.; Zanella, A. Analysis of JAK2 V167F Mutation in Myelodysplastic Syndromes. Blood 2007, 110, 4591. [CrossRef]

62. Papaemmanuil, E.; Gerstung, M.; Malcovati, L.; Tauro, S.; Gundem, G.; Van Loo, P.; Yoon, C.J.; Ellis, P.; Wedge, D.C.; Pellagatti, A.; et al. Clinical and biological implications of driver mutations in myelodysplastic syndromes. Blood 2013, 122, 3616-3627, quiz 3699. [CrossRef] [PubMed]

63. Ingram, W.; Lea, N.C.; Cervera, J.; Germing, U.; Fenaux, P.; Cassinat, B.; Kiladjian, J.J.; Varkonyi, J.; Antunovic, P.; Westwood, N.B.; et al. The JAK2 V617F mutation identifies a subgroup of MDS patients with isolated deletion $5 \mathrm{q}$ and a proliferative bone marrow. Leukemia 2006, 20, 1319-1321. [CrossRef]

64. Cumbo, C.; Tota, G.; Anelli, L.; Zagaria, A.; Specchia, G.; Albano, F. TP53 in Myelodysplastic Syndromes: Recent Biological and Clinical Findings. Int. J. Mol. Sci. 2020, 21, 3432. [CrossRef]

65. Platzbecker, U.; Kordasti, S. Natural born survivors: The inglorious TP53. Blood 2020, 136, 2727-2728. [CrossRef] [PubMed]

66. Kulasekararaj, A.G.; Smith, A.E.; Mian, S.A.; Mohamedali, A.M.; Krishnamurthy, P.; Lea, N.C.; Gaken, J.; Pennaneach, C.; Ireland, R.; Czepulkowski, B.; et al. TP53 mutations in myelodysplastic syndrome are strongly correlated with aberrations of chromosome 5, and correlate with adverse prognosis. Br. J. Haematol. 2013, 160, 660-672. [CrossRef]

67. Ebert, B.L. Deletion 5q in myelodysplastic syndrome: A paradigm for the study of hemizygous deletions in cancer. Leukemia 2009, 23, 1252-1256. [CrossRef]

68. Brooks, C.L.; Gu, W. Ubiquitination, phosphorylation and acetylation: The molecular basis for p53 regulation. Curr. Opin. Cell Biol. 2003, 15, 164-171. [CrossRef]

69. Maya, R.; Balass, M.; Kim, S.T.; Shkedy, D.; Leal, J.F.; Shifman, O.; Moas, M.; Buschmann, T.; Ronai, Z.; Shiloh, Y.; et al. ATMdependent phosphorylation of Mdm2 on serine 395: Role in p53 activation by DNA damage. Genes Dev. 2001, 15, 1067-1077. [CrossRef]

70. Da Silva-Coelho, P.; Kroeze, L.I.; Yoshida, K.; Koorenhof-Scheele, T.N.; Knops, R.; van de Locht, L.T.; de Graaf, A.O.; Massop, M.; Sandmann, S.; Dugas, M.; et al. Clonal evolution in myelodysplastic syndromes. Nat. Commun. 2017, 8, 15099. [CrossRef]

71. Makishima, H.; Yoshizato, T.; Yoshida, K.; Sekeres, M.A.; Radivoyevitch, T.; Suzuki, H.; Przychodzen, B.; Nagata, Y.; Meggendorfer, M.; Sanada, M.; et al. Dynamics of clonal evolution in myelodysplastic syndromes. Nat. Genet. 2017, 49, 204-212. [CrossRef] [PubMed]

72. Davis, A.; Gao, R.; Navin, N. Tumor evolution: Linear, branching, neutral or punctuated? Biochim. Biophys. Acta. Rev. Cancer 2017, 1867, 151-161. [CrossRef]

73. Blyth, K.; Cameron, E.R.; Neil, J.C. The RUNX genes: Gain or loss of function in cancer. Nat. Rev. Cancer 2005, 5, 376-387. [CrossRef] [PubMed]

74. Kuo, M.C.; Liang, D.C.; Huang, C.F.; Shih, Y.S.; Wu, J.H.; Lin, T.L.; Shih, L.Y. RUNX1 mutations are frequent in chronic myelomonocytic leukemia and mutations at the C-terminal region might predict acute myeloid leukemia transformation. Leukemia 2009, 23, 1426-1431. [CrossRef]

75. Chen, C.Y.; Lin, L.I.; Tang, J.L.; Ko, B.S.; Tsay, W.; Chou, W.C.; Yao, M.; Wu, S.J.; Tseng, M.H.; Tien, H.F. RUNX1 gene mutation in primary myelodysplastic syndrome - the mutation can be detected early at diagnosis or acquired during disease progression and is associated with poor outcome. Br. J. Haematol. 2007, 139, 405-414. [CrossRef]

76. Niimi, H.; Harada, H.; Harada, Y.; Ding, Y.; Imagawa, J.; Inaba, T.; Kyo, T.; Kimura, A. Hyperactivation of the RAS signaling pathway in myelodysplastic syndrome with AML1/RUNX1 point mutations. Leukemia 2006, 20, 635-644. [CrossRef] [PubMed]

77. Scharnhorst, V.; van der Eb, A.J.; Jochemsen, A.G. WT1 proteins: Functions in growth and differentiation. Gene 2001, 273, 141-161. [CrossRef] 
78. Ellisen, L.W.; Carlesso, N.; Cheng, T.; Scadden, D.T.; Haber, D.A. The Wilms tumor suppressor WT1 directs stage-specific quiescence and differentiation of human hematopoietic progenitor cells. EMBO J. 2001, 20, 1897-1909. [CrossRef]

79. Xu, F.; Wu, L.-Y.; He, Q.; Wu, D.; Zhang, Z.; Song, L.-X.; Zhao, Y.-S.; Su, J.-Y.; Zhou, L.-Y.; Guo, J.; et al. Exploration of the role of gene mutations in myelodysplastic syndromes through a sequencing design involving a small number of target genes. Sci. Rep. 2017, 7, 43113. [CrossRef]

80. Huang, Q.S.; Wang, J.Z.; Qin, Y.Z.; Zeng, Q.Z.; Jiang, Q.; Jiang, H.; Lu, J.; Liu, H.X.; Liu, Y.; Wang, J.B.; et al. Overexpression of WT1 and PRAME predicts poor outcomes of patients with myelodysplastic syndromes with thrombocytopenia. Blood Adv. 2019, 3, 3406-3418. [CrossRef] [PubMed]

81. Annesley, C.E.; Rabik, C.; Duffield, A.S.; Rau, R.E.; Magoon, D.; Li, L.; Huff, V.; Small, D.; Loeb, D.M.; Brown, P. Knock-in of the Wt1 R394W mutation causes MDS and cooperates with Flt3/ITD to drive aggressive myeloid neoplasms in mice. Oncotarget 2018, 9, 35313-35326. [CrossRef] [PubMed]

82. Avellino, R.; Havermans, M.; Erpelinck, C.; Sanders, M.A.; Hoogenboezem, R.; van de Werken, H.J.; Rombouts, E.; van Lom, K.; van Strien, P.M.; Gebhard, C.; et al. An autonomous CEBPA enhancer specific for myeloid-lineage priming and neutrophilic differentiation. Blood 2016, 127, 2991-3003. [CrossRef] [PubMed]

83. Toma, A.; Fenaux, P.; Dreyfus, F.; Cordonnier, C. Infections in myelodysplastic syndromes. Haematologica 2012, 97, 1459-1470. [CrossRef] [PubMed]

84. Kato, N.; Kitaura, J.; Doki, N.; Komeno, Y.; Watanabe-Okochi, N.; Togami, K.; Nakahara, F.; Oki, T.; Enomoto, Y.; Fukuchi, Y.; et al. Two types of $\mathrm{C} / \mathrm{EBP} \alpha$ mutations play distinct but collaborative roles in leukemogenesis: Lessons from clinical data and BMT models. Blood 2011, 117, 221-233. [CrossRef] [PubMed]

85. Yu, J.; Li, Y.; Li, T.; Li, Y.; Xing, H.; Sun, H.; Sun, L.; Wan, D.; Liu, Y.; Xie, X.; et al. Gene mutational analysis by NGS and its clinical significance in patients with myelodysplastic syndrome and acute myeloid leukemia. Exp. Hematol. Oncol. 2020, 9, 2. [CrossRef]

86. Sportoletti, P.; Varasano, E.; Rossi, R.; Mupo, A.; Tiacci, E.; Vassiliou, G.; Martelli, M.P.; Falini, B. Mouse models of NPM1-mutated acute myeloid leukemia: Biological and clinical implications. Leukemia 2015, 29, 269-278. [CrossRef] [PubMed]

87. Lindstrom, M.S. NPM1/B23: A Multifunctional Chaperone in Ribosome Biogenesis and Chromatin Remodeling. Biochem. Res. Int. 2011, 2011, 195209. [CrossRef]

88. Bains, A.; Luthra, R.; Medeiros, L.J.; Zuo, Z. FLT3 and NPM1 mutations in myelodysplastic syndromes: Frequency and potential value for predicting progression to acute myeloid leukemia. Am. J. Clin. Pathol. 2011, 135, 62-69. [CrossRef]

89. Falini, B.; Sciabolacci, S.; Falini, L.; Brunetti, L.; Martelli, M.P. Diagnostic and therapeutic pitfalls in NPM1-mutated AML: Notes from the field. Leukemia 2021, 1-14. [CrossRef]

90. Montalban-Bravo, G.; Kanagal-Shamanna, R.; Sasaki, K.; Patel, K.; Ganan-Gomez, I.; Jabbour, E.; Kadia, T.; Ravandi, F.; DiNardo, C.; Borthakur, G.; et al. NPM1 mutations define a specific subgroup of MDS and MDS/MPN patients with favorable outcomes with intensive chemotherapy. Blood Adv. 2019, 3, 922-933. [CrossRef]

91. Pellagatti, A.; Armstrong, R.N.; Steeples, V.; Sharma, E.; Repapi, E.; Singh, S.; Sanchi, A.; Radujkovic, A.; Horn, P.; Dolatshad, H.; et al. Impact of spliceosome mutations on RNA splicing in myelodysplasia: Dysregulated genes/pathways and clinical associations. Blood 2018, 132, 1225-1240. [CrossRef] [PubMed]

92. Chen, H.C.; Cheng, S.C. Functional roles of protein splicing factors. Biosci. Rep. 2012, 32, 345-359. [CrossRef] [PubMed]

93. Scott, L.M.; Rebel, V.I. Acquired mutations that affect pre-mRNA splicing in hematologic malignancies and solid tumors. J. Natl. Cancer Inst. 2013, 105, 1540-1549. [CrossRef] [PubMed]

94. Grosso, A.R.; Martins, S.; Carmo-Fonseca, M. The emerging role of splicing factors in cancer. EMBO Rep. 2008, 9, 1087-1093. [CrossRef] [PubMed]

95. Przychodzen, B.; Jerez, A.; Guinta, K.; Sekeres, M.A.; Padgett, R.; Maciejewski, J.P.; Makishima, H. Patterns of missplicing due to somatic U2AF1 mutations in myeloid neoplasms. Blood 2013, 122, 999-1006. [CrossRef] [PubMed]

96. Walter, M.J.; Graubert, T.A. Clinical Implications of Spliceosome Mutations: Epidemiology, Clonal Hematopoiesis, and Potential Therapeutic Strategies. Blood 2016, 128, SCI-19. [CrossRef]

97. Visconte, V.; Tiu, R.V.; Rogers, H.J. Pathogenesis of myelodysplastic syndromes: An overview of molecular and non-molecular aspects of the disease. Blood Res. 2014, 49, 216-227. [CrossRef] [PubMed]

98. Visconte, V.; Rogers, H.J.; Singh, J.; Barnard, J.; Bupathi, M.; Traina, F.; McMahon, J.; Makishima, H.; Szpurka, H.; Jankowska, A.; et al. SF3B1 haploinsufficiency leads to formation of ring sideroblasts in myelodysplastic syndromes. Blood 2012, 120, $3173-3186$. [CrossRef]

99. Zhu, Y.; Song, D.; Guo, J.; Jin, J.; Tao, Y.; Zhang, Z.; Xu, F.; He, Q.; Li, X.; Chang, C.; et al. U2AF1 mutation promotes tumorigenicity through facilitating autophagy flux mediated by FOXO3a activation in myelodysplastic syndromes. Cell Death Dis. 2021, 12, 655. [CrossRef]

100. Papaemmanuil, E.; Cazzola, M.; Boultwood, J.; Malcovati, L.; Vyas, P.; Bowen, D.; Pellagatti, A.; Wainscoat, J.S.; HellstromLindberg, E.; Gambacorti-Passerini, C.; et al. Somatic SF3B1 mutation in myelodysplasia with ring sideroblasts. N. Engl. J. Med. 2011, 365, 1384-1395. [CrossRef]

101. Woll, P.S.; Kjallquist, U.; Chowdhury, O.; Doolittle, H.; Wedge, D.C.; Thongjuea, S.; Erlandsson, R.; Ngara, M.; Anderson, K.; Deng, Q.; et al. Myelodysplastic syndromes are propagated by rare and distinct human cancer stem cells in vivo. Cancer Cell 2014, 25, 794-808. [CrossRef] 
102. Visconte, V.; Avishai, N.; Mahfouz, R.; Tabarroki, A.; Cowen, J.; Sharghi-Moshtaghin, R.; Hitomi, M.; Rogers, H.J.; Hasrouni, E.; Phillips, J.; et al. Distinct iron architecture in SF3B1-mutant myelodysplastic syndrome patients is linked to an SLC25A37 splice variant with a retained intron. Leukemia 2015, 29, 188-195. [CrossRef]

103. Mian, S.A.; Rouault-Pierre, K.; Smith, A.E.; Seidl, T.; Pizzitola, I.; Kizilors, A.; Kulasekararaj, A.G.; Bonnet, D.; Mufti, G.J. SF3B1 mutant MDS-initiating cells may arise from the haematopoietic stem cell compartment. Nat. Commun. 2015, 6, 10004. [CrossRef]

104. Kim, E.; Ilagan, J.O.; Liang, Y.; Daubner, G.M.; Lee, S.C.; Ramakrishnan, A.; Li, Y.; Chung, Y.R.; Micol, J.B.; Murphy, M.E.; et al. SRSF2 Mutations Contribute to Myelodysplasia by Mutant-Specific Effects on Exon Recognition. Cancer Cell 2015, 27, 617-630. [CrossRef] [PubMed]

105. Mian, S.A.; Smith, A.E.; Kulasekararaj, A.G.; Kizilors, A.; Mohamedali, A.M.; Lea, N.C.; Mitsopoulos, K.; Ford, K.; Nasser, E.; Seidl, T.; et al. Spliceosome mutations exhibit specific associations with epigenetic modifiers and proto-oncogenes mutated in myelodysplastic syndrome. Haematologica 2013, 98, 1058-1066. [CrossRef]

106. Claus, R.; Lubbert, M. Epigenetic targets in hematopoietic malignancies. Oncogene 2003, 22, 6489-6496. [CrossRef]

107. Issa, J.P. Epigenetic changes in the myelodysplastic syndrome. Hematol. Oncol. Clin. N. Am. 2010, 24, 317-330. [CrossRef]

108. Ito, S.; Shen, L.; Dai, Q.; Wu, S.C.; Collins, L.B.; Swenberg, J.A.; He, C.; Zhang, Y. Tet proteins can convert 5-methylcytosine to 5-formylcytosine and 5-carboxylcytosine. Science 2011, 333, 1300-1303. [CrossRef]

109. Khan, H.; Vale, C.; Bhagat, T.; Verma, A. Role of DNA methylation in the pathogenesis and treatment of myelodysplastic syndromes. Semin. Hematol. 2013, 50, 16-37. [CrossRef] [PubMed]

110. Lin, P.; Luo, Y.; Zhu, S.; Maggio, D.; Yang, H.; Hu, C.; Wang, J.; Zhang, H.; Ren, Y.; Zhou, X.; et al. Isocitrate dehydrogenase 2 mutations correlate with leukemic transformation and are predicted by 2-hydroxyglutarate in myelodysplastic syndromes. J. Cancer Res. Clin. Oncol. 2018, 144, 1037-1047. [CrossRef] [PubMed]

111. DiNardo, C.D.; Jabbour, E.; Ravandi, F.; Takahashi, K.; Daver, N.; Routbort, M.; Patel, K.P.; Brandt, M.; Pierce, S.; Kantarjian, H.; et al. IDH1 and IDH2 mutations in myelodysplastic syndromes and role in disease progression. Leukemia 2016, 30, 980-984. [CrossRef]

112. Simard, J.-C.; Cesaro, A.; Chapeton-Montes, J.; Tardif, M.; Antoine, F.; Girard, D.; Tessier, P.A. S100A8 and S100A9 Induce Cytokine Expression and Regulate the NLRP3 Inflammasome via ROS-Dependent Activation of NF-kB1. PLoS ONE 2013, 8, e72138. [CrossRef] [PubMed]

113. Basiorka, A.A.; McGraw, K.L.; Eksioglu, E.A.; Chen, X.; Johnson, J.; Zhang, L.; Zhang, Q.; Irvine, B.A.; Cluzeau, T.; Sallman, D.A.; et al. The NLRP3 inflammasome functions as a driver of the myelodysplastic syndrome phenotype. Blood 2016, 128, 2960-2975. [CrossRef]

114. Maria, V.; Evaggelia, P.; Irene, M.; Maria, P.; Christos, T.; Anastasis, O.; Ioannis, I.; Pavlos, K.; Helen, A.P. Impaired clearance of apoptotic cells leads to HMGB1 release in the bone marrow of patients with myelodysplastic syndromes and induces TLR4-mediated cytokine production. Haematologica 2013, 98, 1206-1215. [CrossRef]

115. Medzhitov, R. Origin and physiological roles of inflammation. Nature 2008, 454, 428-435. [CrossRef] [PubMed]

116. Franceschi, C.; Garagnani, P.; Parini, P.; Giuliani, C.; Santoro, A. Inflammaging: A new immune-metabolic viewpoint for age-related diseases. Nat. Rev. Endocrinol. 2018, 14, 576-590. [CrossRef] [PubMed]

117. Maratheftis, C.I.; Andreakos, E.; Moutsopoulos, H.M.; Voulgarelis, M. Toll-like receptor-4 is up-regulated in hematopoietic progenitor cells and contributes to increased apoptosis in myelodysplastic syndromes. Clin. Cancer Res. 2007, 13, 1154-1160. [CrossRef] [PubMed]

118. Wei, Y.; Dimicoli, S.; Bueso-Ramos, C.; Chen, R.; Yang, H.; Neuberg, D.; Pierce, S.; Jia, Y.; Zheng, H.; Wang, H.; et al. Toll-like receptor alterations in myelodysplastic syndrome. Leukemia 2013, 27, 1832-1840. [CrossRef]

119. Sallman, D.A.; Cluzeau, T.; Basiorka, A.A.; List, A. Unraveling the Pathogenesis of MDS: The NLRP3 Inflammasome and Pyroptosis Drive the MDS Phenotype. Front. Oncol. 2016, 6, 151. [CrossRef]

120. Sallman, D.A.; List, A. The central role of inflammatory signaling in the pathogenesis of myelodysplastic syndromes. Blood 2019, 133, 1039-1048. [CrossRef]

121. Sakhdari, A.; Class, C.; Montalban-Bravo, G.; Sasaki, K.; Bueso-Ramos, C.E.; Patel, K.P.; Khoury, J.D.; Kantarjian, H.M.; GarciaManero, G.; Medeiros, L.J.; et al. Loss of EZH2 Protein Expression in Myelodysplastic Syndrome Correlates with EZH2 Mutation and Portends a Worse Outcome. Blood 2019, 134, 3016. [CrossRef]

122. Stasik, S.; Middeke, J.M.; Kramer, M.; Rollig, C.; Kramer, A.; Scholl, S.; Hochhaus, A.; Crysandt, M.; Brummendorf, T.H.; Naumann, R.; et al. EZH2 mutations and impact on clinical outcome: An analysis in 1,604 patients with newly diagnosed acute myeloid leukemia. Haematologica 2020, 105, e228-e231. [CrossRef] [PubMed]

123. Mochizuki-Kashio, M.; Aoyama, K.; Sashida, G.; Oshima, M.; Tomioka, T.; Muto, T.; Wang, C.; Iwama, A. Ezh2 loss in hematopoietic stem cells predisposes mice to develop heterogeneous malignancies in an Ezh1-dependent manner. Blood 2015, 126, 1172-1183. [CrossRef] [PubMed]

124. Itzykson, R.; Kosmider, O.; Fenaux, P. Somatic mutations and epigenetic abnormalities in myelodysplastic syndromes. Best Pr. Res. Clin. Haematol. 2013, 26, 355-364. [CrossRef]

125. Abdel-Wahab, O.; Adli, M.; LaFave, L.M.; Gao, J.; Hricik, T.; Shih, A.H.; Pandey, S.; Patel, J.P.; Chung, Y.R.; Koche, R.; et al. ASXL1 mutations promote myeloid transformation through loss of PRC2-mediated gene repression. Cancer Cell 2012, 22, 180-193. [CrossRef] 
126. Fisher, C.L.; Berger, J.; Randazzo, F.; Brock, H.W. A human homolog of Additional sex combs, ADDITIONAL SEX COMBS-LIKE 1, maps to chromosome 20q11. Gene 2003, 306, 115-126. [CrossRef]

127. Nolte, F.; Hofmann, W.K. Myelodysplastic syndromes: Molecular pathogenesis and genomic changes. Ann. Hematol. 2008, 87, 777-795. [CrossRef] [PubMed]

128. Boultwood, J.; Perry, J.; Pellagatti, A.; Fernandez-Mercado, M.; Fernandez-Santamaria, C.; Calasanz, M.J.; Larrayoz, M.J.; Garcia-Delgado, M.; Giagounidis, A.; Malcovati, L.; et al. Frequent mutation of the polycomb-associated gene ASXL1 in the myelodysplastic syndromes and in acute myeloid leukemia. Leukemia 2010, 24, 1062-1065. [CrossRef] [PubMed]

129. Gelsi-Boyer, V.; Trouplin, V.; Adelaide, J.; Bonansea, J.; Cervera, N.; Carbuccia, N.; Lagarde, A.; Prebet, T.; Nezri, M.; Sainty, D.; et al. Mutations of polycomb-associated gene ASXL1 in myelodysplastic syndromes and chronic myelomonocytic leukaemia. Br. J. Haematol. 2009, 145, 788-800. [CrossRef] [PubMed]

130. Rocquain, J.; Carbuccia, N.; Trouplin, V.; Raynaud, S.; Murati, A.; Nezri, M.; Tadrist, Z.; Olschwang, S.; Vey, N.; Birnbaum, D.; et al. Combined mutations of ASXL1, CBL, FLT3, IDH1, IDH2, JAK2, KRAS, NPM1, NRAS, RUNX1, TET2 and WT1 genes in myelodysplastic syndromes and acute myeloid leukemias. BMC Cancer 2010, 10, 401. [CrossRef]

131. Chen, T.C.; Hou, H.A.; Chou, W.C.; Tang, J.L.; Kuo, Y.Y.; Chen, C.Y.; Tseng, M.H.; Huang, C.F.; Lai, Y.J.; Chiang, Y.C.; et al. Dynamics of ASXL1 mutation and other associated genetic alterations during disease progression in patients with primary myelodysplastic syndrome. Blood Cancer J. 2014, 4, e177. [CrossRef] [PubMed]

132. Thol, F.; Friesen, I.; Damm, F.; Yun, H.; Weissinger, E.M.; Krauter, J.; Wagner, K.; Chaturvedi, A.; Sharma, A.; Wichmann, M.; et al. Prognostic significance of ASXL1 mutations in patients with myelodysplastic syndromes. J. Clin. Oncol. 2011, 29, 2499-2506. [CrossRef] [PubMed]

133. Kitamura, T. ASXL1 mutations gain a function. Blood 2018, 131, 274-275. [CrossRef] [PubMed]

134. Smith, A.E.; Mohamedali, A.M.; Kulasekararaj, A.; Lim, Z.; Gaken, J.; Lea, N.C.; Przychodzen, B.; Mian, S.A.; Nasser, E.E.; Shooter, C.; et al. Next-generation sequencing of the TET2 gene in 355 MDS and CMML patients reveals low-abundance mutant clones with early origins, but indicates no definite prognostic value. Blood 2010, 116, 3923-3932. [CrossRef] [PubMed]

135. Kosmider, O.; Gelsi-Boyer, V.; Cheok, M.; Grabar, S.; Della-Valle, V.; Picard, F.; Viguie, F.; Quesnel, B.; Beyne-Rauzy, O.; Solary, E.; et al. TET2 mutation is an independent favorable prognostic factor in myelodysplastic syndromes (MDSs). Blood 2009, 114, 3285-3291. [CrossRef]

136. Jiang, S. Tet 2 at the interface between cancer and immunity. Commun. Biol. 2020, 3, 667. [CrossRef]

137. Quivoron, C.; Couronne, L.; Della Valle, V.; Lopez, C.K.; Plo, I.; Wagner-Ballon, O.; Do Cruzeiro, M.; Delhommeau, F.; Arnulf, B.; Stern, M.H.; et al. TET2 inactivation results in pleiotropic hematopoietic abnormalities in mouse and is a recurrent event during human lymphomagenesis. Cancer Cell 2011, 20, 25-38. [CrossRef]

138. Grignano, E.; Jachiet, V.; Fenaux, P.; Ades, L.; Fain, O.; Mekinian, A. Autoimmune manifestations associated with myelodysplastic syndromes. Ann. Hematol. 2018, 97, 2015-2023. [CrossRef]

139. Aggarwal, S.; van de Loosdrecht, A.A.; Alhan, C.; Ossenkoppele, G.J.; Westers, T.M.; Bontkes, H.J. Role of immune responses in the pathogenesis of low-risk MDS and high-risk MDS: Implications for immunotherapy. Br. J. Haematol. 2011, 153, 568-581. [CrossRef]

140. Kotsianidis, I.; Bouchliou, I.; Nakou, E.; Spanoudakis, E.; Margaritis, D.; Christophoridou, A.V.; Anastasiades, A.; Tsigalou, C.; Bourikas, G.; Karadimitris, A.; et al. Kinetics, function and bone marrow trafficking of CD4+CD25+FOXP3+ regulatory T cells in myelodysplastic syndromes (MDS). Leukemia 2009, 23, 510-518. [CrossRef]

141. Zou, J.X.; Rollison, D.E.; Boulware, D.; Chen, D.T.; Sloand, E.M.; Pfannes, L.V.; Goronzy, J.J.; Bai, F.; Painter, J.S.; Wei, S.; et al. Altered naive and memory CD4+ T-cell homeostasis and immunosenescence characterize younger patients with myelodysplastic syndrome. Leukemia 2009, 23, 1288-1296. [CrossRef] [PubMed]

142. Pardoll, D.M. The blockade of immune checkpoints in cancer immunotherapy. Nat. Rev. Cancer 2012, 12, 252-264. [CrossRef] [PubMed]

143. Chen, L.; Flies, D.B. Molecular mechanisms of T cell co-stimulation and co-inhibition. Nat. Rev. Immunol. 2013, 13, 227-242. [CrossRef]

144. Boddu, P.; Kantarjian, H.; Garcia-Manero, G.; Allison, J.; Sharma, P.; Daver, N. The emerging role of immune checkpoint based approaches in AML and MDS. Leuk. Lymphoma 2018, 59, 790-802. [CrossRef] [PubMed]

145. Yi, M.; Niu, M.; Xu, L.; Luo, S.; Wu, K. Regulation of PD-L1 expression in the tumor microenvironment. J. Hematol. Oncol. 2021, 14, 10. [CrossRef]

146. Yang, H.; Bueso-Ramos, C.; DiNardo, C.; Estecio, M.R.; Davanlou, M.; Geng, Q.R.; Fang, Z.; Nguyen, M.; Pierce, S.; Wei, Y.; et al. Expression of PD-L1, PD-L2, PD-1 and CTLA4 in myelodysplastic syndromes is enhanced by treatment with hypomethylating agents. Leukemia 2014, 28, 1280-1288. [CrossRef] [PubMed]

147. Cheng, P.; Eksioglu, E.A.; Chen, X.; Kandell, W.; Le Trinh, T.; Cen, L.; Qi, J.; Sallman, D.A.; Zhang, Y.; Tu, N.; et al. S100A9induced overexpression of PD-1/PD-L1 contributes to ineffective hematopoiesis in myelodysplastic syndromes. Leukemia 2019, 33, 2034-2046. [CrossRef]

148. Montalban-Bravo, G.; Garcia-Manero, G.; Jabbour, E. Therapeutic choices after hypomethylating agent resistance for myelodysplastic syndromes. Curr. Opin. Hematol. 2018, 25, 146-153. [CrossRef]

149. Mohammadzadeh, A. Co-inhibitory receptors, transcription factors and tolerance. Int. Immunopharmacol. $2020,84,106572$. [CrossRef] [PubMed] 
150. Shastri, A.; Will, B.; Steidl, U.; Verma, A. Stem and progenitor cell alterations in myelodysplastic syndromes. Blood 2017, 129, 1586-1594. [CrossRef]

151. Asayama, T.; Tamura, H.; Ishibashi, M.; Kuribayashi-Hamada, Y.; Onodera-Kondo, A.; Okuyama, N.; Yamada, A.; Shimizu, M.; Moriya, K.; Takahashi, H.; et al. Functional expression of Tim-3 on blasts and clinical impact of its ligand galectin-9 in myelodysplastic syndromes. Oncotarget 2017, 8, 88904-88917. [CrossRef]

152. Zeidan, A.M.; Komrokji, R.S.; Brunner, A.M. TIM-3 pathway dysregulation and targeting in cancer. Expert Rev. Anticancer 2021, 21, 523-534. [CrossRef]

153. Tao, J.; Han, D.; Gao, S.; Zhang, W.; Yu, H.; Liu, P.; Fu, R.; Li, L.; Shao, Z. CD8(+) T cells exhaustion induced by myeloidderived suppressor cells in myelodysplastic syndromes patients might be through TIM3/Gal-9 pathway. J. Cell Mol. Med. 2020, 24, 1046-1058. [CrossRef] [PubMed]

154. Kikushige, Y.; Miyamoto, T.; Yuda, J.; Jabbarzadeh-Tabrizi, S.; Shima, T.; Takayanagi, S.; Niiro, H.; Yurino, A.; Miyawaki, K.; Takenaka, K.; et al. A TIM-3/Gal-9 Autocrine Stimulatory Loop Drives Self-Renewal of Human Myeloid Leukemia Stem Cells and Leukemic Progression. Cell Stem Cell 2015, 17, 341-352. [CrossRef]

155. Barreyro, L.; Chlon, T.M.; Starczynowski, D.T. Chronic immune response dysregulation in MDS pathogenesis. Blood 2018, 132, 1553-1560. [CrossRef] [PubMed]

156. Cull, A.H.; Snetsinger, B.; Buckstein, R.; Wells, R.A.; Rauh, M.J. Tet2 restrains inflammatory gene expression in macrophages. Exp. Hematol. 2017, 55, 56-70.e13. [CrossRef] [PubMed]

157. Zeng, Q.; Shu, J.; Hu, Q.; Zhou, S.H.; Qian, Y.M.; Hu, M.H.; Hu, L.Y.; Wang, Y.G.; Zhou, Y.M.; Lu, J.H. Apoptosis in human myelodysplastic syndrome CD34+ cells is modulated by the upregulation of TLRs and histone H4 acetylation via a beta-arrestin 1 dependent mechanism. Exp. Cell Res. 2016, 340, 22-31. [CrossRef] [PubMed]

158. Bjorklund, A.T.; Carlsten, M.; Sohlberg, E.; Liu, L.L.; Clancy, T.; Karimi, M.; Cooley, S.; Miller, J.S.; Klimkowska, M.; Schaffer, M.; et al. Complete Remission with Reduction of High-Risk Clones following Haploidentical NK-Cell Therapy against MDS and AML. Clin. Cancer Res. 2018, 24, 1834-1844. [CrossRef]

159. Carlsten, M.; Baumann, B.C.; Simonsson, M.; Jadersten, M.; Forsblom, A.M.; Hammarstedt, C.; Bryceson, Y.T.; Ljunggren, H.G.; Hellstrom-Lindberg, E.; Malmberg, K.J. Reduced DNAM-1 expression on bone marrow NK cells associated with impaired killing of CD34+ blasts in myelodysplastic syndrome. Leukemia 2010, 24, 1607-1616. [CrossRef]

160. Carlsten, M.; Jaras, M. Natural Killer Cells in Myeloid Malignancies: Immune Surveillance, NK Cell Dysfunction, and Pharmacological Opportunities to Bolster the Endogenous NK Cells. Front. Immunol. 2019, 10, 2357. [CrossRef]

161. Porzsolt, F.; Heimpel, H. Natural killer cell activity in preleukaemia. Lancet 1982, 1, 449. [CrossRef]

162. Takaku, S.; Takaku, F. Natural killer cell activity and preleukaemia. Lancet 1981, 2, 1178. [CrossRef]

163. Ma, L.; Delforge, M.; van Duppen, V.; Verhoef, G.; Emanuel, B.; Boogaerts, M.; Hagemeijer, A.; Vandenberghe, P. Circulating myeloid and lymphoid precursor dendritic cells are clonally involved in myelodysplastic syndromes. Leukemia 2004, 18, 1451-1456. [CrossRef] [PubMed]

164. Bento, L.C.; Bacal, N.S.; Rocha, F.A.; Severino, P.; Marti, L.C. Bone Marrow Monocytes and Derived Dendritic Cells from Myelodysplastic Patients Have Functional Abnormalities Associated with Defective Response to Bacterial Infection. J. Immunol. 2020, 204, 2098-2109. [CrossRef] [PubMed]

165. Ganan-Gomez, I.; Wei, Y.; Starczynowski, D.T.; Colla, S.; Yang, H.; Cabrero-Calvo, M.; Bohannan, Z.S.; Verma, A.; Steidl, U.; Garcia-Manero, G. Deregulation of innate immune and inflammatory signaling in myelodysplastic syndromes. Leukemia 2015, 29, 1458-1469. [CrossRef] [PubMed]

166. Han, Y.; Wang, H.; Shao, Z. Monocyte-Derived Macrophages Are Impaired in Myelodysplastic Syndrome. J. Immunol. Res. 2016, 2016, 5479013. [CrossRef]

167. Haddad, F.; Daver, N. Targeting CD47/SIRP $\alpha$ in Acute Myeloid Leukemia and Myelodysplastic Syndrome: Preclinical and Clinical Developments of Magrolimab. J. Immunother. Precis. Oncol. 2021, 4, 67-71. [CrossRef]

168. Murata, Y.; Saito, Y.; Kotani, T.; Matozaki, T. CD47-signal regulatory protein alpha signaling system and its application to cancer immunotherapy. Cancer Sci. 2018, 109, 2349-2357. [CrossRef]

169. Eladl, E.; Tremblay-LeMay, R.; Rastgoo, N.; Musani, R.; Chen, W.; Liu, A.; Chang, H. Role of CD47 in Hematological Malignancies. J. Hematol. Oncol. 2020, 13, 96. [CrossRef]

170. Jiang, H.; Fu, R.; Wang, H.; Li, L.; Liu, H.; Shao, Z. CD47 is expressed abnormally on hematopoietic cells in myelodysplastic syndrome. Leuk. Res. 2013, 37, 907-910. [CrossRef]

171. Soto-Pantoja, D.R.; Terabe, M.; Ghosh, A.; Ridnour, L.A.; DeGraff, W.G.; Wink, D.A.; Berzofsky, J.A.; Roberts, D.D. CD47 in the Tumor Microenvironment Limits Cooperation between Antitumor T-cell Immunity and Radiotherapy. Cancer Res. 2014, 74, 6771-6783. [CrossRef] [PubMed]

172. Sorm, F.; Piskala, A.; Cihak, A.; Vesely, J. 5-Azacytidine, a new, highly effective cancerostatic. Experientia 1964, 20, 202-203. [CrossRef] [PubMed]

173. Boultwood, J.; Wainscoat, J.S. Gene silencing by DNA methylation in haematological malignancies. Br. J. Haematol. 2007, 138 , 3-11. [CrossRef] [PubMed]

174. Joeckel, T.E.; Lubbert, M. Clinical results with the DNA hypomethylating agent 5-aza-2'-deoxycytidine (decitabine) in patients with myelodysplastic syndromes: An update. Semin. Hematol. 2012, 49, 330-341. [CrossRef] 
175. Cheson, B.D.; Bennett, J.M.; Kantarjian, H.; Pinto, A.; Schiffer, C.A.; Nimer, S.D.; Lowenberg, B.; Beran, M.; de Witte, T.M.; Stone, R.M.; et al. Report of an international working group to standardize response criteria for myelodysplastic syndromes. Blood 2000, 96, 3671-3674. [PubMed]

176. Steensma, D.P.; Baer, M.R.; Slack, J.L.; Buckstein, R.; Godley, L.A.; Garcia-Manero, G.; Albitar, M.; Larsen, J.S.; Arora, S.; Cullen, M.T;; et al. Multicenter study of decitabine administered daily for 5 days every 4 weeks to adults with myelodysplastic syndromes: The alternative dosing for outpatient treatment (ADOPT) trial. J. Clin. Oncol. 2009, 27, 3842-3848. [CrossRef]

177. Schmiedel, B.J.; Arelin, V.; Gruenebach, F.; Krusch, M.; Schmidt, S.M.; Salih, H.R. Azacytidine impairs NK cell reactivity while decitabine augments NK cell responsiveness toward stimulation. Int. J. Cancer 2011, 128, 2911-2922. [CrossRef] [PubMed]

178. Kwon, Y.-R.; Kim, H.J.; Sohn, M.-J.; Lim, J.-Y.; Park, K.-S.; Lee, S.; Chung, N.-G.; Jeong, D.-C.; Min, C.-K.; Kim, Y.-J. Effects of decitabine on allogeneic immune reactions of donor lymphocyte infusion via activation of dendritic cells. Exp. Hematol. Oncol. 2020, 9, 22. [CrossRef]

179. Stomper, J.; Rotondo, J.C.; Greve, G.; Lübbert, M. Hypomethylating agents (HMA) for the treatment of acute myeloid leukemia and myelodysplastic syndromes: Mechanisms of resistance and novel HMA-based therapies. Leukemia 2021, 35, 1873-1889. [CrossRef]

180. Gañán-Gómez, I.; Alfonso, A.; Ogoti, Y.; Yang, H.; Montalban-Bravo, G.; Yu, A.C.; Marchesini, M.; Bueso-Ramos, C.E.; Takahashi, K.; Clise-Dwyer, K.; et al. Hematopoietic Architecture of MDS before and after Progression Reveals Two Biologically Distinct Disease Subtypes. Blood 2016, 128, 4310. [CrossRef]

181. Nahas, M.R.; Stroopinsky, D.; Rosenblatt, J.; Cole, L.; Pyzer, A.R.; Anastasiadou, E.; Sergeeva, A.; Ephraim, A.; Washington, A.; Orr, S.; et al. Hypomethylating agent alters the immune microenvironment in acute myeloid leukaemia (AML) and enhances the immunogenicity of a dendritic cell/AML vaccine. Br. J. Haematol. 2019, 185, 679-690. [CrossRef]

182. Xiong, H.; Mittman, S.; Rodriguez, R.; Moskalenko, M.; Pacheco-Sanchez, P.; Yang, Y.; Nickles, D.; Cubas, R. Anti-PD-L1 Treatment Results in Functional Remodeling of the Macrophage Compartment. Cancer Res. 2019, 79, 1493-1506. [CrossRef]

183. Jia, X.; Yang, W.; Zhou, X.; Han, L.; Shi, J. Influence of demethylation on regulatory T and Th17 cells in myelodysplastic syndrome. Oncol. Lett. 2020, 19, 442-448. [CrossRef] [PubMed]

184. Costantini, B.; Kordasti, S.Y.; Kulasekararaj, A.G.; Jiang, J.; Seidl, T.; Abellan, P.P.; Mohamedali, A.; Thomas, N.S.; Farzaneh, F.; Mufti, G.J. The effects of 5-azacytidine on the function and number of regulatory $\mathrm{T}$ cells and T-effectors in myelodysplastic syndrome. Haematologica 2013, 98, 1196-1205. [CrossRef] [PubMed]

185. Diesch, J.; Zwick, A.; Garz, A.K.; Palau, A.; Buschbeck, M.; Gotze, K.S. A clinical-molecular update on azanucleoside-based therapy for the treatment of hematologic cancers. Clin. Epigenet. 2016, 8, 71. [CrossRef] [PubMed]

186. Qin, T.; Jelinek, J.; Si, J.; Shu, J.; Issa, J.P. Mechanisms of resistance to 5-aza-2'-deoxycytidine in human cancer cell lines. Blood 2009, 113, 659-667. [CrossRef]

187. Duchmann, M.; Itzykson, R. Clinical update on hypomethylating agents. Int. J. Hematol. 2019, 110, 161-169. [CrossRef]

188. Valencia, A.; Masala, E.; Rossi, A.; Martino, A.; Sanna, A.; Buchi, F.; Canzian, F.; Cilloni, D.; Gaidano, V.; Voso, M.T.; et al. Expression of nucleoside-metabolizing enzymes in myelodysplastic syndromes and modulation of response to azacitidine. Leukemia 2014, 28, 621-628. [CrossRef]

189. Sripayap, P.; Nagai, T.; Uesawa, M.; Kobayashi, H.; Tsukahara, T.; Ohmine, K.; Muroi, K.; Ozawa, K. Mechanisms of resistance to azacitidine in human leukemia cell lines. Exp. Hematol. 2014, 42, 294-306.e292. [CrossRef]

190. Gruber, E.; Franich, R.L.; Shortt, J.; Johnstone, R.W.; Kats, L.M. Distinct and overlapping mechanisms of resistance to azacytidine and guadecitabine in acute myeloid leukemia. Leukemia 2020, 34, 3388-3392. [CrossRef]

191. Orskov, A.D.; Treppendahl, M.B.; Skovbo, A.; Holm, M.S.; Friis, L.S.; Hokland, M.; Gronbaek, K. Hypomethylation and upregulation of PD-1 in T cells by azacytidine in MDS/AML patients: A rationale for combined targeting of PD-1 and DNA methylation. Oncotarget 2015, 6, 9612-9626. [CrossRef] [PubMed]

192. Garcia-Manero, G.; Gore, S.D.; Cogle, C.; Ward, R.; Shi, T.; Macbeth, K.J.; Laille, E.; Giordano, H.; Sakoian, S.; Jabbour, E.; et al. Phase I study of oral azacitidine in myelodysplastic syndromes, chronic myelomonocytic leukemia, and acute myeloid leukemia. J. Clin. Oncol. 2011, 29, 2521-2527. [CrossRef] [PubMed]

193. Laille, E.; Shi, T.; Garcia-Manero, G.; Cogle, C.R.; Gore, S.D.; Hetzer, J.; Kumar, K.; Skikne, B.; MacBeth, K.J. Pharmacokinetics and Pharmacodynamics with Extended Dosing of CC-486 in Patients with Hematologic Malignancies. PLoS ONE 2015, 10, e0135520. [CrossRef]

194. Garcia-Manero, G.; Gore, S.D.; Kambhampati, S.; Scott, B.; Tefferi, A.; Cogle, C.R.; Edenfield, W.J.; Hetzer, J.; Kumar, K.; Laille, E.; et al. Efficacy and safety of extended dosing schedules of CC-486 (oral azacitidine) in patients with lower-risk myelodysplastic syndromes. Leukemia 2016, 30, 889-896. [CrossRef] [PubMed]

195. Garcia-Manero, G.; Santini, V.; Almeida, A.; Platzbecker, U.; Jonasova, A.; Silverman, L.R.; Falantes, J.; Reda, G.; Buccisano, F.; Fenaux, P.; et al. Phase III, Randomized, Placebo-Controlled Trial of CC-486 (Oral Azacitidine) in Patients With Lower-Risk Myelodysplastic Syndromes. J. Clin. Oncol. 2021, 39, 1426-1436. [CrossRef]

196. Garcia-Manero, G.; Daver, N.G.; Xu, J.; Chao, M.; Chung, T.; Tan, A.; Wang, V.; Wei, A.; Vyas, P.; Sallman, D.A. Magrolimab + azacitidine versus azacitidine + placebo in untreated higher risk (HR) myelodysplastic syndrome (MDS): The phase 3, randomized, ENHANCE study. J. Clin. Oncol. 2021, 39, TPS7055. [CrossRef] 
197. Kantarjian, H.M.; Roboz, G.J.; Kropf, P.L.; Yee, K.W.L.; O'Connell, C.L.; Tibes, R.; Walsh, K.J.; Podoltsev, N.A.; Griffiths, E.A.; Jabbour, E.; et al. Guadecitabine (SGI-110) in treatment-naive patients with acute myeloid leukaemia: Phase 2 results from a multicentre, randomised, phase $1 / 2$ trial. Lancet Oncol. 2017, 18, 1317-1326. [CrossRef]

198. Issa, J.J.; Roboz, G.; Rizzieri, D.; Jabbour, E.; Stock, W.; O'Connell, C.; Yee, K.; Tibes, R.; Griffiths, E.A.; Walsh, K.; et al. Safety and tolerability of guadecitabine (SGI-110) in patients with myelodysplastic syndrome and acute myeloid leukaemia: A multicentre, randomised, dose-escalation phase 1 study. Lancet Oncol. 2015, 16, 1099-1110. [CrossRef]

199. Sebert, M.; Renneville, A.; Bally, C.; Peterlin, P.; Beyne-Rauzy, O.; Legros, L.; Gourin, M.P.; Sanhes, L.; Wattel, E.; Gyan, E.; et al. A phase II study of guadecitabine in higher-risk myelodysplastic syndrome and low blast count acute myeloid leukemia after azacitidine failure. Haematologica 2019, 104, 1565-1571. [CrossRef]

200. Astex-Pharmaceuticals; Otuka-Harmaceuticals. Astex and Otsuka Announce Results of Phase 3 ASTRAL-2 and ASTRAL-3 Studies of Guadecitabine (SGI-110) in Patients with Previously Treated Acute Myeloid Leukemia (AML) and Myelodysplastic Syndromes or Chronic Myelomonocytic Leukemia (MDS/CMML). Available online: https://astx.com/astex-and-otsukaannounce-results-of-phase-3-astral-2-and-astral-3-studies-of-guadecitabine-sgi-110-in-patients-with-previously-treatedacute-myeloid-leukemia-aml-and-myelodysplastic-syndromes-or / (accessed on 17 September 2021).

201. Savona, M.R.; Odenike, O.; Amrein, P.C.; Steensma, D.P.; DeZern, A.E.; Michaelis, L.C.; Faderl, S.; Harb, W.; Kantarjian, H.; Lowder, J.; et al. An oral fixed-dose combination of decitabine and cedazuridine in myelodysplastic syndromes: A multicentre, open-label, dose-escalation, phase 1 study. Lancet Haematol. 2019, 6, e194-e203. [CrossRef]

202. Garcia-Manero, G.; Griffiths, E.A.; Steensma, D.P.; Roboz, G.J.; Wells, R.; McCloskey, J.; Odenike, O.; DeZern, A.E.; Yee, K.; Busque, L.; et al. Oral cedazuridine/decitabine for MDS and CMML: A phase 2 pharmacokinetic/pharmacodynamic randomized crossover study. Blood 2020, 136, 674-683. [CrossRef]

203. Garcia-Manero, G.; McCloskey, J.; Griffiths, E.A.; Yee, K.W.L.; Zeidan, A.M.; Al-Kali, A.; Dao, K.-H.; Deeg, H.J.; Patel, P.A.; Sabloff, M.; et al. Pharmacokinetic Exposure Equivalence and Preliminary Efficacy and Safety from a Randomized Cross over Phase 3 Study (ASCERTAIN study) of an Oral Hypomethylating Agent ASTX727 (cedazuridine/decitabine) Compared to IV Decitabine. Blood 2019, 134, 846. [CrossRef]

204. Jehangir, W.; Karabachev, A.; Jahangir, T.; Umyarova, E. Myelodysplastic Syndrome with Transfusion Dependence Treated with Venetoclax. Case Rep. Hematol. 2020, 2020, 9031067. [CrossRef]

205. Pagliuca, S.; Gurnari, C.; Visconte, V. Molecular Targeted Therapy in Myelodysplastic Syndromes: New Options for Tailored Treatments. Cancers 2021, 13, 784. [CrossRef]

206. Gangat, N.; Tefferi, A. Venetoclax-based chemotherapy in acute and chronic myeloid neoplasms: Literature survey and practice points. Blood Cancer J. 2020, 10, 122. [CrossRef] [PubMed]

207. Saliba, A.N.; John, A.J.; Kaufmann, S.H. Resistance to venetoclax and hypomethylating agents in acute myeloid leukemia. Cancer Drug Resist. 2021, 4, 125-142. [CrossRef] [PubMed]

208. Jilg, S.; Hauch, R.T.; Kauschinger, J.; Buschhorn, L.; Odinius, T.O.; Dill, V.; Muller-Thomas, C.; Herold, T.; Prodinger, P.M.; Schmidt, B.; et al. Venetoclax with azacitidine targets refractory MDS but spares healthy hematopoiesis at tailored dose. Exp. Hematol. Oncol. 2019, 8, 9. [CrossRef]

209. Wei, A.H.; Garcia, J.S.; Borate, U.; Fong, C.Y.; Baer, M.R.; Nolte, F.; Peterlin, P.; Jurcic, J.G.; Garcia-Manero, G.; Hong, W.-J.; et al. A Phase $1 \mathrm{~b}$ Study Evaluating the Safety and Efficacy of Venetoclax in Combination with Azacitidine in Treatment-Naïve Patients with Higher-Risk Myelodysplastic Syndrome. Blood 2019, 134, 568. [CrossRef]

210. Bewersdorf, J.P.; Zeidan, A.M. Management of patients with higher-risk myelodysplastic syndromes after failure of hypomethylating agents: What is on the horizon? Best Pr. Res. Clin. Haematol. 2021, 34, 101245. [CrossRef]

211. Ball, B.J.; Famulare, C.A.; Stein, E.M.; Tallman, M.S.; Derkach, A.; Roshal, M.; Gill, S.I.; Manning, B.M.; Koprivnikar, J.; McCloskey, J.; et al. Venetoclax and hypomethylating agents (HMAs) induce high response rates in MDS, including patients after HMA therapy failure. Blood Adv. 2020, 4, 2866-2870. [CrossRef] [PubMed]

212. Zeidan, A.M.; Garcia, J.S.; Fenaux, P.; Platzbecker, U.; Miyazaki, Y.; Xiao, Z.-J.; Zhou, Y.; Naqvi, K.; Kye, S.; Garcia-Manero, G. Phase 3 VERONA study of venetoclax with azacitidine to assess change in complete remission and overall survival in treatmentnaïve higher-risk myelodysplastic syndromes. J. Clin. Oncol. 2021, 39, TPS7054. [CrossRef]

213. Pollyea, D.A.; Stevens, B.M.; Jones, C.L.; Winters, A.; Pei, S.; Minhajuddin, M.; D'Alessandro, A.; Culp-Hill, R.; Riemondy, K.A.; Gillen, A.E.; et al. Venetoclax with azacitidine disrupts energy metabolism and targets leukemia stem cells in patients with acute myeloid leukemia. Nat. Med. 2018, 24, 1859-1866. [CrossRef] [PubMed]

214. Jones, C.L.; Stevens, B.M.; Pollyea, D.A.; Culp-Hill, R.; Reisz, J.A.; Nemkov, T.; Gehrke, S.; Gamboni, F.; Krug, A.; Winters, A.; et al. Nicotinamide Metabolism Mediates Resistance to Venetoclax in Relapsed Acute Myeloid Leukemia Stem Cells. Cell Stem Cell 2020, 27, 748-764.e744. [CrossRef]

215. Dinardo, C.D.; Watts, J.M.; Stein, E.M.; De Botton, S.; Fathi, A.T.; Prince, G.T.; Stein, A.S.; Foran, J.M.; Stone, R.M.; Patel, P.A.; et al. Ivosidenib (AG-120) Induced Durable Remissions and Transfusion Independence in Patients with IDH1-Mutant Relapsed or Refractory Myelodysplastic Syndrome: Results from a Phase 1 Dose Escalation and Expansion Study. Blood 2018, $132,1812$. [CrossRef]

216. Zeng, Z.; Konopleva, M. Concurrent inhibition of IDH and methyltransferase maximizes therapeutic efficacy in IDH mutant acute myeloid leukemia. Haematologica 2021, 106, 324-326. [CrossRef] [PubMed] 
217. Gil-Perez, A.; Montalban-Bravo, G. Management of myelodysplastic syndromes after failure of response to hypomethylating agents. Adv. Hematol 2019, 10, 2040620719847059. [CrossRef] [PubMed]

218. Foran, J.M.; DiNardo, C.D.; Watts, J.M.; Stein, E.M.; De Botton, S.; Fathi, A.T.; Prince, G.T.; Stein, A.; Stone, R.M.; Patel, P.A.; et al. Ivosidenib (AG-120) in Patients with IDH1-Mutant Relapsed/Refractory Myelodysplastic Syndrome: Updated Enrollment of a Phase 1 Dose Escalation and Expansion Study. Blood 2019, 134, 4254. [CrossRef]

219. Dinardo, C.D.; Foran, J.M.; Watts, J.M.; Stein, E.M.; Botton, S.D.; Fathi, A.T.; Prince, G.T.; Stein, A.S.; Stone, R.M.; Patel, P.A.; et al. MDS-265: Ivosidenib (IVO) in Patients with IDH1-Mutant Relapsed/Refractory Myelodysplastic Syndrome (R/R MDS): Updated Enrollment of a Phase 1 Dose Escalation and Expansion Study. Clin. Lymphoma Myeloma Leuk. 2020, 20, S321. [CrossRef]

220. Cortes, J.E.; Wang, E.S.; Watts, J.M.; Lee, S.; Baer, M.R.; Dao, K.-H.; Dinner, S.; Yang, J.; Donnellan, W.B.; Schwarer, A.P.; et al Olutasidenib (FT-2102) Induces Rapid Remissions in Patients with IDH1-Mutant Myelodysplastic Syndrome: Results of Phase $1 / 2$ Single Agent Treatment and Combination with Azacitidine. Blood 2019, 134, 674. [CrossRef]

221. Watts, J.M.; Baer, M.R.; Lee, S.; Yang, J.; Dinner, S.N.; Prebet, T.; Schiller, G.J.; Seiter, K.; Ferrell, P.B.; Kelly, P.F.; et al. A phase 1 dose escalation study of the IDH1m inhibitor, FT-2102, in patients with acute myeloid leukemia (AML) or myelodysplastic syndrome (MDS). J. Clin. Oncol. 2018, 36, 7009. [CrossRef]

222. Stein, E.M.; DiNardo, C.D.; Pollyea, D.A.; Fathi, A.T.; Roboz, G.J.; Altman, J.K.; Stone, R.M.; DeAngelo, D.J.; Levine, R.L.; Flinn, I.W.; et al. Enasidenib in mutant IDH2 relapsed or refractory acute myeloid leukemia. Blood 2017, 130, 722-731. [CrossRef] [PubMed]

223. Stein, E.M.; Fathi, A.T.; DiNardo, C.D.; Pollyea, D.A.; Roboz, G.J.; Collins, R.; Sekeres, M.A.; Stone, R.M.; Attar, E.C.; Frattini, M.G.; et al. Enasidenib in patients with mutant IDH2 myelodysplastic syndromes: A phase 1 subgroup analysis of the multicentre, AG221-C-001 trial. Lancet Haematol. 2020, 7, e309-e319. [CrossRef]

224. Santini, V. Enasidenib: A magic bullet for myelodysplastic syndromes? Lancet Haematol 2020, 7, e275-e276. [CrossRef]

225. Richard-Carpentier, G.; DeZern, A.E.; Takahashi, K.; Konopleva, M.Y.; Loghavi, S.; Masarova, L.; Alvarado, Y.; Ravandi, F.; Montalban Bravo, G.; Naqvi, K.; et al. Preliminary Results from the Phase II Study of the IDH2-Inhibitor Enasidenib in Patients with High-Risk IDH2-Mutated Myelodysplastic Syndromes (MDS). Blood 2019, 134, 678. [CrossRef]

226. Venugopal, S.; Dinardo, C.D.; Takahashi, K.; Konopleva, M.; Loghavi, S.; Borthakur, G.; Dezern, A.E.; Masarova, L.; Daver, N.G.; Short, N.J.; et al. Phase II study of the IDH2-inhibitor enasidenib in patients with high-risk IDH2-mutated myelodysplastic syndromes (MDS). J. Clin. Oncol. 2021, 39, 7010. [CrossRef]

227. Strati, P.; Kantarjian, H.; Ravandi, F.; Nazha, A.; Borthakur, G.; Daver, N.; Kadia, T.; Estrov, Z.; Garcia-Manero, G.; Konopleva, M.; et al. Phase I/II trial of the combination of midostaurin (PKC412) and 5-azacytidine for patients with acute myeloid leukemia and myelodysplastic syndrome. Am. J. Hematol. 2015, 90, 276-281. [CrossRef]

228. Fischer, T.; Stone, R.M.; Deangelo, D.J.; Galinsky, I.; Estey, E.; Lanza, C.; Fox, E.; Ehninger, G.; Feldman, E.J.; Schiller, G.J.; et al. Phase IIB trial of oral Midostaurin (PKC412), the FMS-like tyrosine kinase 3 receptor (FLT3) and multi-targeted kinase inhibitor, in patients with acute myeloid leukemia and high-risk myelodysplastic syndrome with either wild-type or mutated FLT3. J. Clin. Oncol. 2010, 28, 4339-4345. [CrossRef]

229. Rao, A.; Rizzieri, D.A.; Vanegas, E.; Moore, J.O.; Gockerman, J.P.; Diehl, L.F.; Adams, D.; Warzecho, J.; Decastro, C. Pilot Study of Sorafenib for Myelodysplastic Syndrome. Blood 2012, 120, 4948. [CrossRef]

230. Macdonald, D.A.; Assouline, S.E.; Brandwein, J.; Kamel-Reid, S.; Eisenhauer, E.A.; Couban, S.; Caplan, S.; Foo, A.; Walsh, W.; Leber, B. A phase I/II study of sorafenib in combination with low dose cytarabine in elderly patients with acute myeloid leukemia or high-risk myelodysplastic syndrome from the National Cancer Institute of Canada Clinical Trials Group: Trial IND.186. Leuk. Lymphoma 2013, 54, 760-766. [CrossRef]

231. Abdelall, W.; Kantarjian, H.M.; Borthakur, G.; Garcia-Manero, G.; Patel, K.P.; Jabbour, E.J.; Daver, N.G.; Kadia, T.; Gborogen, R.A.; Konopleva, M.; et al. The Combination of Quizartinib with Azacitidine or Low Dose Cytarabine Is Highly Active in Patients (Pts) with FLT3-ITD Mutated Myeloid Leukemias: Interim Report of a Phase I/II Trial. Blood 2016, 128, 1642. [CrossRef]

232. Armstrong, R.N.; Steeples, V.; Singh, S.; Sanchi, A.; Boultwood, J.; Pellagatti, A. Splicing factor mutations in the myelodysplastic syndromes: Target genes and therapeutic approaches. Adv. Biol. Regul. 2018, 67, 13-29. [CrossRef] [PubMed]

233. Pellagatti, A.; Boultwood, J. Splicing factor gene mutations in the myelodysplastic syndromes: Impact on disease phenotype and therapeutic applications. Adv. Biol. Regul. 2017, 63, 59-70. [CrossRef]

234. Taylor, J.; Lee, S.C. Mutations in spliceosome genes and therapeutic opportunities in myeloid malignancies. Genes Chromosomes Cancer 2019, 58, 889-902. [CrossRef] [PubMed]

235. Eskens, F.A.; Ramos, F.J.; Burger, H.; O’Brien, J.P.; Piera, A.; de Jonge, M.J.; Mizui, Y.; Wiemer, E.A.; Carreras, M.J.; Baselga, J.; et al. Phase I pharmacokinetic and pharmacodynamic study of the first-in-class spliceosome inhibitor E7107 in patients with advanced solid tumors. Clin. Cancer Res. 2013, 19, 6296-6304. [CrossRef] [PubMed]

236. Brierley, C.K.; Steensma, D.P. Targeting Splicing in the Treatment of Myelodysplastic Syndromes and Other Myeloid Neoplasms. Curr. Hematol. Malig. Rep. 2016, 11, 408-415. [CrossRef] [PubMed]

237. Seiler, M.; Yoshimi, A.; Darman, R.; Chan, B.; Keaney, G.; Thomas, M.; Agrawal, A.A.; Caleb, B.; Csibi, A.; Sean, E.; et al. H3B-8800, an orally available small-molecule splicing modulator, induces lethality in spliceosome-mutant cancers. Nat. Med. 2018, 24, 497-504. [CrossRef] 
238. Steensma, D.P.; Wermke, M.; Klimek, V.M.; Greenberg, P.L.; Font, P.; Komrokji, R.S.; Yang, J.; Brunner, A.M.; Carraway, H.E.; Ades, L.; et al. Results of a Clinical Trial of H3B-8800, a Splicing Modulator, in Patients with Myelodysplastic Syndromes (MDS), Acute Myeloid Leukemia (AML) or Chronic Myelomonocytic Leukemia (CMML). Blood 2019, 134, 673. [CrossRef]

239. Ventura, A.; Kirsch, D.G.; McLaughlin, M.E.; Tuveson, D.A.; Grimm, J.; Lintault, L.; Newman, J.; Reczek, E.E.; Weissleder, R.; Jacks, T. Restoration of p53 function leads to tumour regression in vivo. Nature 2007, 445, 661-665. [CrossRef]

240. Martins, C.P.; Brown-Swigart, L.; Evan, G.I. Modeling the Therapeutic Efficacy of p53 Restoration in Tumors. Cell 2006, 127, 1323-1334. [CrossRef]

241. Bykov, V.J.; Zhang, Q.; Zhang, M.; Ceder, S.; Abrahmsen, L.; Wiman, K.G. Targeting of Mutant p53 and the Cellular Redox Balance by APR-246 as a Strategy for Efficient Cancer Therapy. Front. Oncol. 2016, 6, 21. [CrossRef]

242. Lambert, J.M.; Gorzov, P.; Veprintsev, D.B.; Söderqvist, M.; Segerbäck, D.; Bergman, J.; Fersht, A.R.; Hainaut, P.; Wiman, K.G.; Bykov, V.J. PRIMA-1 reactivates mutant p53 by covalent binding to the core domain. Cancer Cell 2009, 15, 376-388. [CrossRef]

243. Sallman, D.A.; DeZern, A.E.; Garcia-Manero, G.; Steensma, D.P.; Roboz, G.J.; Sekeres, M.A.; Cluzeau, T.; Sweet, K.L.; McLemore, A.; McGraw, K.L.; et al. Eprenetapopt (APR-246) and Azacitidine in TP53-Mutant Myelodysplastic Syndromes. J. Clin. Oncol. 2021, 39, 1584-1594. [CrossRef]

244. Garcia-Manero, G.; Tallman, M.S.; Martinelli, G.; Ribrag, V.; Yang, H.; Balakumaran, A.; Chlosta, S.; Zhang, Y.; Smith, B.D. Pembrolizumab, a PD-1 Inhibitor, in Patients with Myelodysplastic Syndrome (MDS) after Failure of Hypomethylating Agent Treatment. Blood 2016, 128, 345. [CrossRef]

245. Zeidan, A.M.; Knaus, H.A.; Robinson, T.M.; Towlerton, A.M.H.; Warren, E.H.; Zeidner, J.F.; Blackford, A.L.; Duffield, A.S.; Rizzieri, D.; Frattini, M.G.; et al. A Multi-center Phase I Trial of Ipilimumab in Patients with Myelodysplastic Syndromes following Hypomethylating Agent Failure. Clin. Cancer Res. 2018, 24, 3519-3527. [CrossRef] [PubMed]

246. Chien, K.S.; Borthakur, G.M.; Naqvi, K.; Daver, N.G.; Cortes, J.E.; DiNardo, C.D.; Jabbour, E.; Andreeff, M.; Alvarado, Y.; Bose, P.; et al. Updated Preliminary Results from a Phase II Study Combining Azacitidine and Pembrolizumab in Patients with Higher-Risk Myelodysplastic Syndrome. Blood 2019, 134, 4240. [CrossRef]

247. Garcia-Manero, G.; Sasaki, K.; Montalban-Bravo, G.; Daver, N.G.; Jabbour, E.J.; Alvarado, Y.; DiNardo, C.D.; Ravandi, F.; Borthakur, G.; Bose, P.; et al. A Phase II Study of Nivolumab or Ipilimumab with or without Azacitidine for Patients with Myelodysplastic Syndrome (MDS). Blood 2018, 132, 465. [CrossRef]

248. Garcia-Manero, G.; Daver, N.G.; Montalban-Bravo, G.; Jabbour, E.J.; DiNardo, C.D.; Kornblau, S.M.; Bose, P.; Alvarado, Y.; Ohanian, M.; Borthakur, G.; et al. A Phase II Study Evaluating the Combination of Nivolumab (Nivo) or Ipilimumab (Ipi) with Azacitidine in Pts with Previously Treated or Untreated Myelodysplastic Syndromes (MDS). Blood 2016, 128, 344. [CrossRef]

249. Zeidan, A.M.; Cavenagh, J.; Voso, M.T.; Taussig, D.; Tormo, M.; Boss, I.; Copeland, W.B.; Gray, V.E.; Previtali, A.; O'Connor, T.; et al. Efficacy and Safety of Azacitidine (AZA) in Combination with the Anti-PD-L1 Durvalumab (durva) for the Front-Line Treatment of Older Patients (pts) with Acute Myeloid Leukemia (AML) Who Are Unfit for Intensive Chemotherapy (IC) and Pts with Higher-Risk Myelodysplastic Syndromes (HR-MDS): Results from a Large, International, Randomized Phase 2 Study. Blood 2019, 134, 829. [CrossRef]

250. Gerds, A.T.; Scott, B.L.; Greenberg, P.L.; Khaled, S.K.; Lin, T.L.; Pollyea, D.A.; Verma, A.; Dail, M.; Green, C.; Ma, C.; et al. PD-L1 Blockade with Atezolizumab in Higher-Risk Myelodysplastic Syndrome: An Initial Safety and Efficacy Analysis. Blood 2018, 132, 466. [CrossRef]

251. Brunner, A.M.; Esteve, J.; Porkka, K.; Knapper, S.; Vey, N.; Scholl, S.; Garcia-Manero, G.; Wermke, M.; Janssen, J.; Traer, E.; et al. Efficacy and Safety of Sabatolimab (MBG453) in Combination with Hypomethylating Agents (HMAs) in Patients with Acute Myeloid Leukemia (AML) and High-Risk Myelodysplastic Syndrome (HR-MDS): Updated Results from a Phase 1b Study. Blood 2020, 136, 1-2. [CrossRef]

252. Borate, U.; Esteve, J.; Porkka, K.; Knapper, S.; Vey, N.; Scholl, S.; Garcia-Manero, G.; Wermke, M.; Janssen, J.; Traer, E.; et al. Phase Ib Study of the Anti-TIM-3 Antibody MBG453 in Combination with Decitabine in Patients with High-Risk Myelodysplastic Syndrome (MDS) and Acute Myeloid Leukemia (AML). Blood 2019, 134, 570. [CrossRef]

253. Chao, M.P.; Takimoto, C.H.; Feng, D.D.; McKenna, K.; Gip, P.; Liu, J.; Volkmer, J.-P.; Weissman, I.L.; Majeti, R. Therapeutic Targeting of the Macrophage Immune Checkpoint CD47 in Myeloid Malignancies. Front. Oncol. 2020, 9, 1380. [CrossRef]

254. Sallman, D.A.; Asch, A.S.; Al Malki, M.M.; Lee, D.J.; Donnellan, W.B.; Marcucci, G.; Kambhampati, S.; Daver, N.G.; Garcia-Manero, G.; Komrokji, R.S.; et al. The First-in-Class Anti-CD47 Antibody Magrolimab (5F9) in Combination with Azacitidine Is Effective in MDS and AML Patients: Ongoing Phase 1b Results. Blood 2019, 134, 569. [CrossRef]

255. Sallman, D.A.; Malki, M.A.; Asch, A.S.; Lee, D.J.; Kambhampati, S.; Donnellan, W.B.; Bradley, T.J.; Vyas, P.; Jeyakumar, D.; Marcucci, G.; et al. Tolerability and efficacy of the first-in-class anti-CD47 antibody magrolimab combined with azacitidine in MDS and AML patients: Phase Ib results. J. Clin. Oncol. 2020, 38, 7507. [CrossRef]

256. Stevens, B.M.; Zhang, W.; Pollyea, D.A.; Winters, A.; Gutman, J.; Smith, C.; Budde, E.; Forman, S.J.; Jordan, C.T.; Purev, E. CD123 CAR T cells for the treatment of myelodysplastic syndrome. Exp. Hematol. 2019, 74, 52-63.e53. [CrossRef] [PubMed]

257. Li, L.J.; Tao, J.L.; Fu, R.; Wang, H.Q.; Jiang, H.J.; Yue, L.Z.; Zhang, W.; Liu, H.; Shao, Z.H. Increased CD34 + CD38 -CD123 + cells in myelodysplastic syndrome displaying malignant features similar to those in AML. Int. J. Hematol. 2014, 100, 60-69. [CrossRef]

258. Houchins, J.P.; Yabe, T.; McSherry, C.; Miyokawa, N.; Bach, F.H. Isolation and characterization of NK cell or NK/T cell-specific cDNA clones. J. Mol. Cell Immunol. 1990, 4, 295-304; discussion 305-296. [PubMed] 
259. Carapito, R.; Bahram, S. Genetics, genomics, and evolutionary biology of NKG2D ligands. Immunol. Rev. 2015, 267, 88-116. [CrossRef] [PubMed]

260. Epling-Burnette, P.K.; Bai, F.; Painter, J.S.; Rollison, D.E.; Salih, H.R.; Krusch, M.; Zou, J.; Ku, E.; Zhong, B.; Boulware, D.; et al. Reduced natural killer (NK) function associated with high-risk myelodysplastic syndrome (MDS) and reduced expression of activating NK receptors. Blood 2007, 109, 4816-4824. [CrossRef]

261. Gacerez, A.T.; Arellano, B.; Sentman, C.L. How Chimeric Antigen Receptor Design Affects Adoptive T Cell Therapy. J. Cell Physiol. 2016, 231, 2590-2598. [CrossRef]

262. Giuliani, M.; Poggi, A. Checkpoint Inhibitors and Engineered Cells: New Weapons for Natural Killer Cell Arsenal Against Hematological Malignancies. Cells 2020, 9, 1578. [CrossRef] [PubMed]

263. Zhang, T.; Barber, A.; Sentman, C.L. Generation of antitumor responses by genetic modification of primary human $\mathrm{T}$ cells with a chimeric NKG2D receptor. Cancer Res. 2006, 66, 5927-5933. [CrossRef] [PubMed]

264. Barber, A.; Meehan, K.R.; Sentman, C.L. Treatment of multiple myeloma with adoptively transferred chimeric NKG2D receptorexpressing T cells. Gene 2011, 18, 509-516. [CrossRef] [PubMed]

265. Baumeister, S.H.; Murad, J.; Werner, L.; Daley, H.; Trebeden-Negre, H.; Gicobi, J.K.; Schmucker, A.; Reder, J.; Sentman, C.L.; Gilham, D.E.; et al. Phase I Trial of Autologous CAR T Cells Targeting NKG2D Ligands in Patients with AML/MDS and Multiple Myeloma. Cancer Immunol. Res. 2019, 7, 100-112. [CrossRef] [PubMed]

266. Sallman, D.A.; Brayer, J.; Sagatys, E.M.; Lonez, C.; Breman, E.; Agaugué, S.; Verma, B.; Gilham, D.E.; Lehmann, F.F.; Davila, M.L. NKG2D-based chimeric antigen receptor therapy induced remission in a relapsed/refractory acute myeloid leukemia patient. Haematologica 2018, 103, e424-e426. [CrossRef]

267. Spear, P.; Wu, M.R.; Sentman, M.L.; Sentman, C.L. NKG2D ligands as therapeutic targets. Cancer Immun. 2013, $13,8$.

268. Le Bert, N.; Gasser, S. Advances in NKG2D ligand recognition and responses by NK cells. Immunol. Cell Biol. 2014, 92, 230-236. [CrossRef]

269. Hong, S.; Rybicki, L.; Corrigan, D.; Hamilton, B.K.; Sobecks, R.; Kalaycio, M.; Dean, R.M.; Hill, B.T.; Pohlman, B.; Jagadeesh, D.; et al. Targeted Treatment and Survival Following Relapse after Allogeneic Hematopoietic Cell Transplantation for Acute Leukemia and MDS in the Contemporary Era. Blood 2019, 134, 4567. [CrossRef]

270. Claiborne, J.; Bandyopathyay, D.; Roberts, C.; Hawks, K.; Aziz, M.; Simmons, G.; Wiedl, C.; Chung, H.; Clark, W.; McCarty, J.; et al. Managing post allograft relapse of myeloid neoplasms: Azacitidine and donor lymphocyte infusions as salvage therapy. Leuk. Lymphoma 2019, 60, 2733-2743. [CrossRef]

271. Zeiser, R.; Beelen, D.W.; Bethge, W.; Bornhauser, M.; Bug, G.; Burchert, A.; Christopeit, M.; Duyster, J.; Finke, J.; Gerbitz, A.; et al. Biology-Driven Approaches to Prevent and Treat Relapse of Myeloid Neoplasia after Allogeneic Hematopoietic Stem Cell Transplantation. Biol. Blood Marrow Transplant. 2019, 25, e128-e140. [CrossRef]

272. Lulla, P.; Naik, S.; Tzannou, I.; Mukhi, S.; Kuvalekar, M.; Robertson, C.; Ramos, C.A.; Carrum, G.; Kamble, R.T.; Gee, A.P.; et al. Administering Leukemia-Directed Donor Lymphocytes to Patients with AML or MDS to Prevent or Treat Post-Allogeneic HSCT Relapse. Biol. Blood Marrow Transplant. 2019, 25, S10-S11. [CrossRef]

273. Epperly, R.; Gottschalk, S.; Velasquez, M.P. A Bump in the Road: How the Hostile AML Microenvironment Affects CAR T Cell Therapy. Front. Oncol. 2020, 10. [CrossRef] [PubMed]

274. Warlick, E.D.; Miller, J.S. Myelodysplastic syndromes: The role of the immune system in pathogenesis. Leuk. Lymphoma 2011, 52, 2045-2049. [CrossRef] [PubMed] 